\title{
THE IMPACT OF INDIVIDUAL VARIABLES AMONG TWELFTH GRADE STUDENTS AND THEIR PARENTS ON THE LEVEL OF PROFESSIONAL AWARENESS: A CASE STUDY IN AL BATINAH REGION SOUTH THE SULTANATE OF OMAN
}

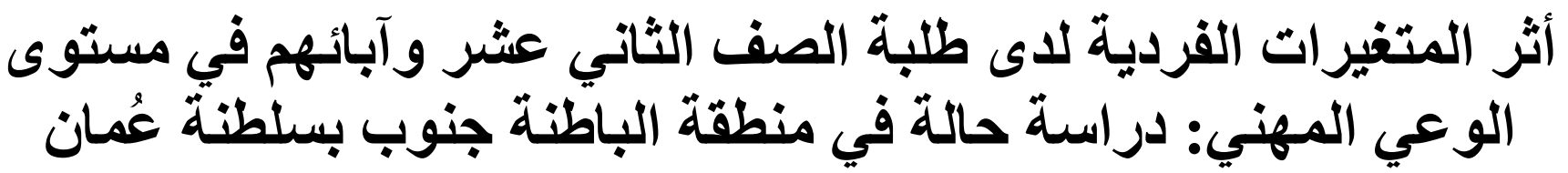

\author{
عادل بن تحمل بن ناصر الكندي \\ Adil Mohammed Al-Kindi ${ }^{1 *}$, Dawood Abdulmalek Al-Hidabi ${ }^{2}$, and Ahmad Jumaa Al- \\ Riymi $^{3}$ \\ ${ }^{1} \mathrm{Ph} . \mathrm{D}$. Candidate at the Faculty of Education, International Islamic University Malaysia (IIUM), \\ Adel.alkindi@moe.om \\ ${ }^{2}$ Prof. Dr. at the Kulliyyah of Education, International Islamic University Malaysia (IIUM), \\ Dawood@iium.edu.my \\ ${ }^{3}$ Prof. Dr. at the Rustaq College of Education, Oman: Ahmed.rus@cas.edu.om \\ ${ }^{*}$ Corresponding author
}

\begin{abstract}
This quantitative study discussed the effect of individual variables among students and their parents on the level of occupational awareness. The problem emerges from the presence of many individual variables that affect the student's professional choice, including the student's knowledge of himself and his capabilities and his ability to make the right professional decision, in light of variables: gender, educational level of the father, family income level, age of the father. Therefore, the aim of the study was to discuss the effect of variables (gender, educational level of the father, level of family income, age of the father) in finding statistically significant differences in occupational awareness among twelfth grade students and their parents. I followed the descriptive analytical research methodology. The study population consisted of all 12th graders in the region. They are (6125) male and female students, distributed among (37) schools in six states. The sample consisted of (312) students. The number of males (152) and females (160). These students meet their parents (312). A unified scale for occupational awareness for students and parents was designed, it included (47) items distributed in six areas: the field of vocational guidance activities, the direction towards work, professional inclinations and capabilities, professional decision-making, professional attention, and vocational planning. Statistical treatment: Descriptive analysis, $(\mathrm{T})$ test, and ANOVA (One-Way) test were used. The results showed that there were statistically significant differences in occupational awareness among twelfth grade students according to the
\end{abstract}


gender variable and in favor of females. There are no statistically significant differences in Professional awareness among the twelfth grade students according to the variables (the educational level of the father, the level of the family's income, and the age of the father) There are no statistically significant differences in the professional awareness of the fathers of the twelfth grade students according to the variables (the educational level, the level of family income, and age).

Keywords: variables, occupational awareness, students, parents.

\section{الملـخــص}

ناقثتثْ هذه الدر اسة الكمية أثر المتغيرات الفردية لدى الطلبة و آبائهم في مستوى الوعي المهني. تبرز

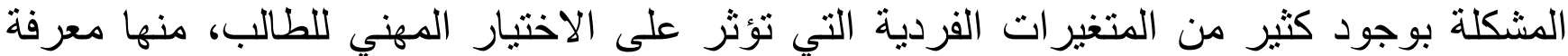

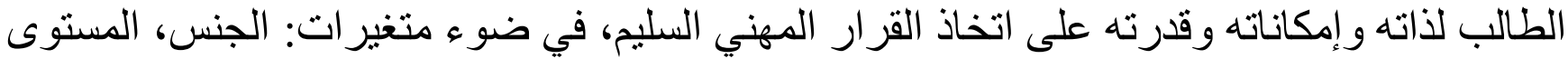

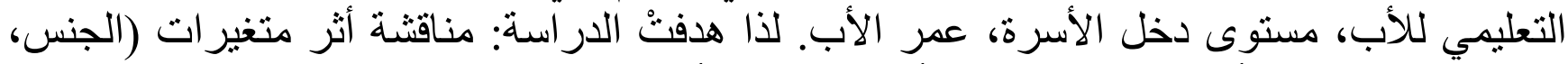

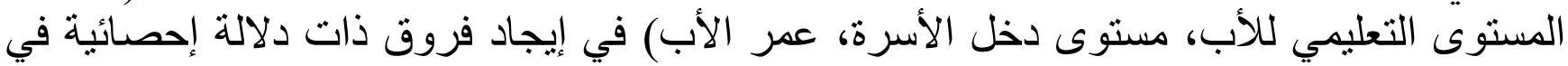

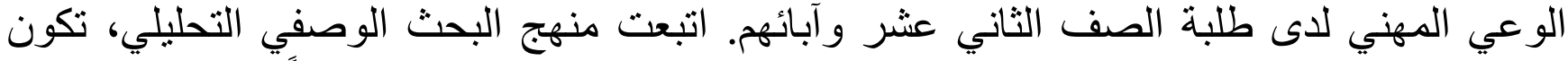

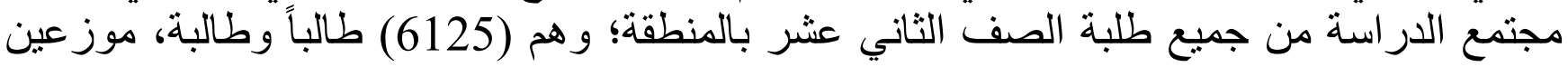

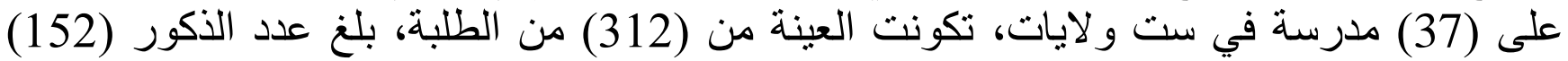
و الإناث (160)، يقابل هؤلاء الطلبة آبائهم وعددهم (312). تم تصميم مقياس موحد للوعي المهني

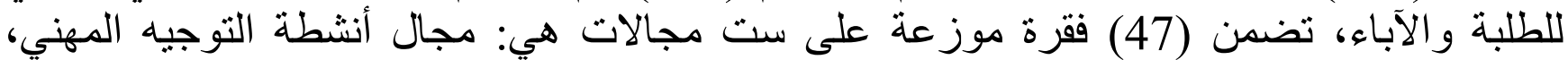

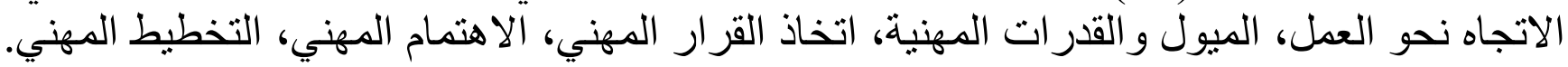

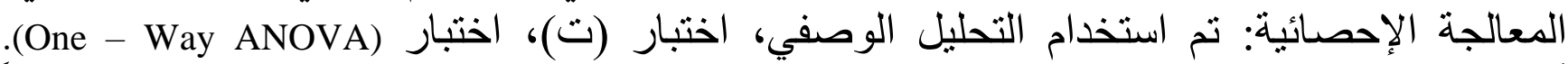

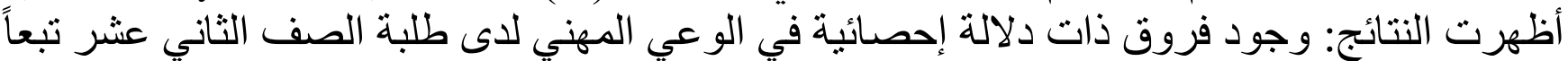

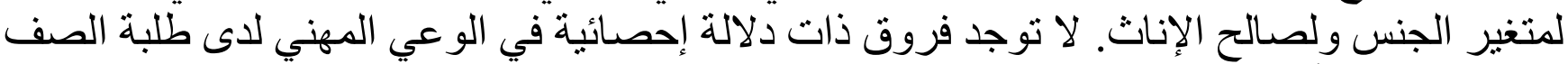

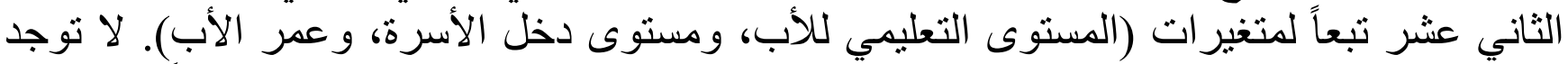
فروق ذات دلالة إحصائية في الوعي المهني لدى آباء طلبة الصف التفي الثاني عشر تبعاً لمتغيرات

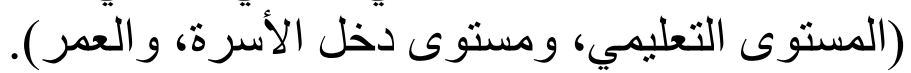
كلمات مفتاحية: المتغير ات، الوعي المهني، الطلبة، الآباء.

المقدمة:

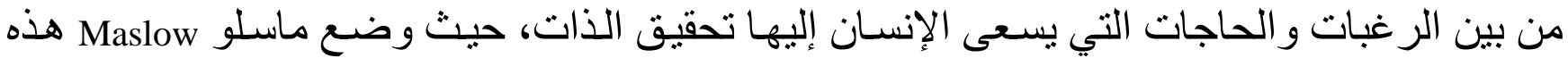

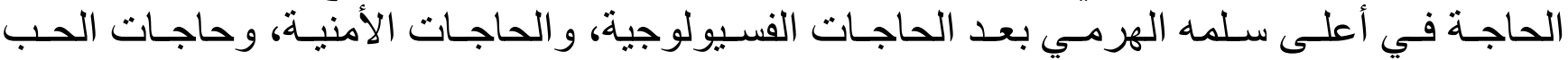

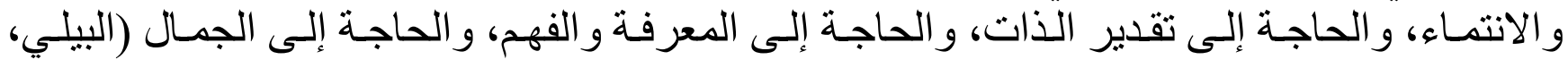
و العمادي، و الصمادي، والتهاء، 2001).

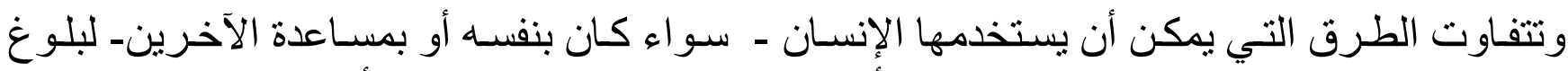
وتحقيق هذه الحاجة و إثباعها؛ لكونها حاجة أساسية من حاجاته، على اعتبار أن تحقيق الذات يسـاعد 


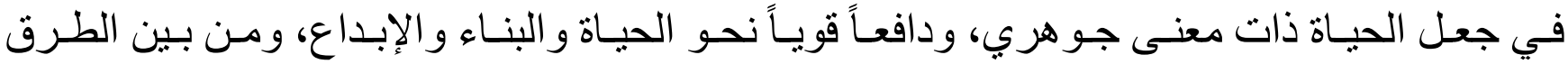

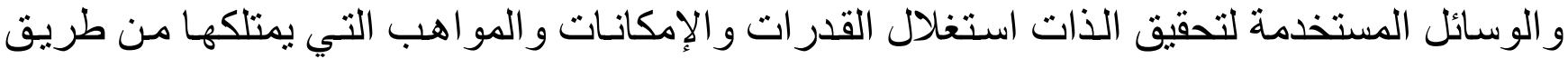

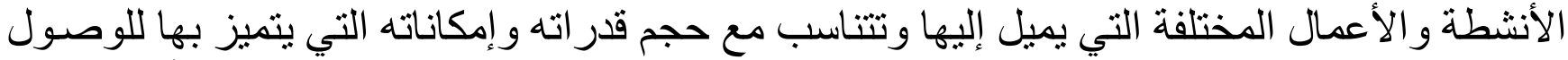

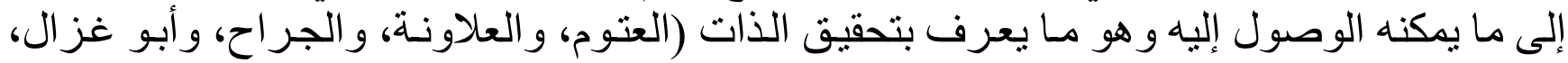

.(2005

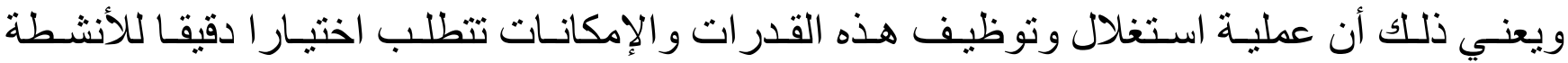

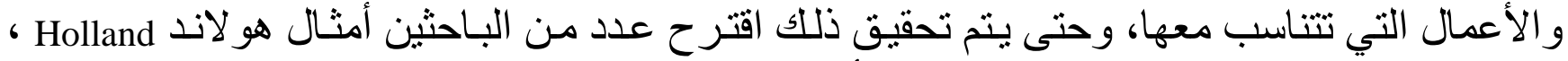

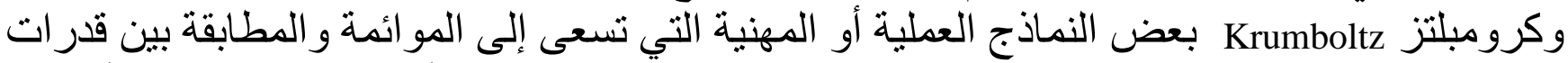

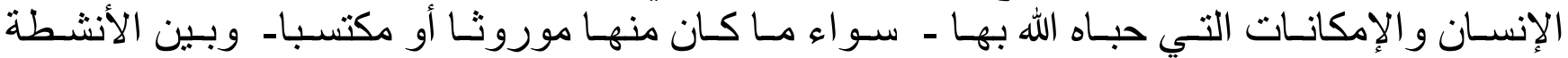

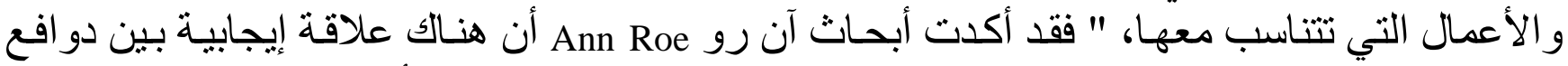

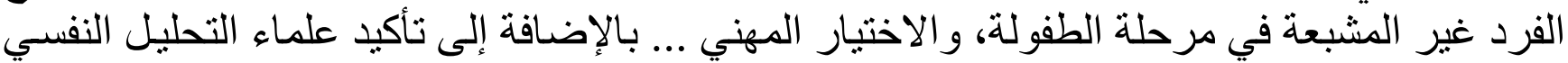

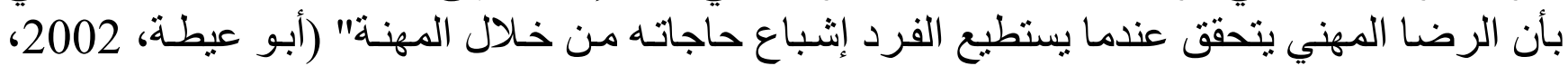

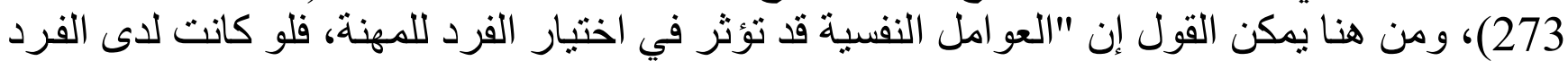

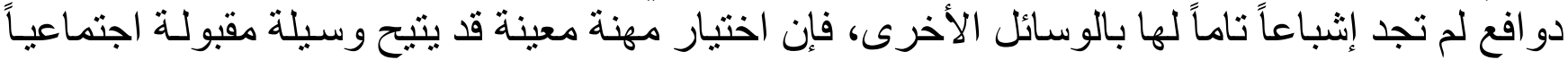

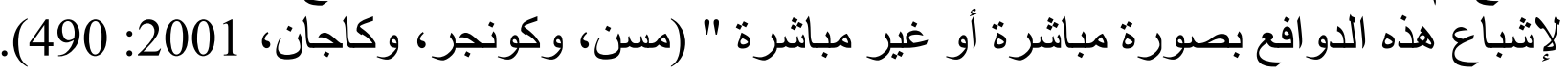

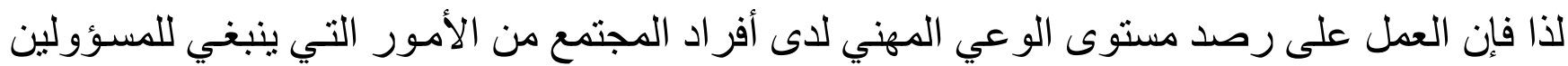

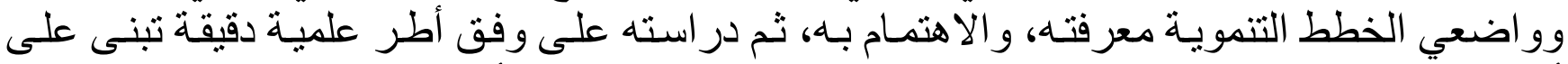

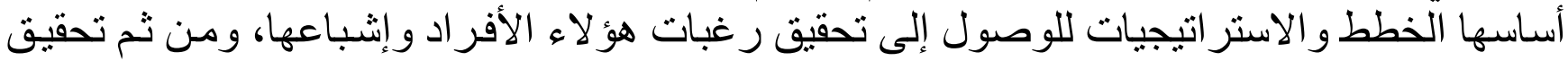

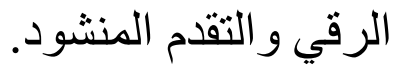

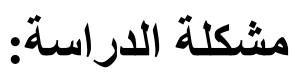

تأتي أهميـة تنميـة الوعي المهني لدى طلبـة التعليم الأساسـي ومـا بعده لتتناسـب و الاتجاهـات العالميـة

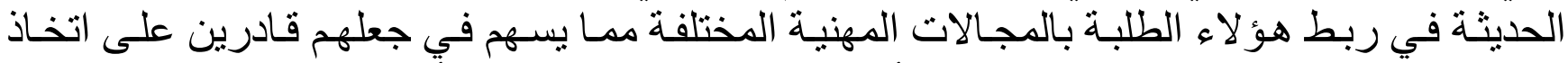

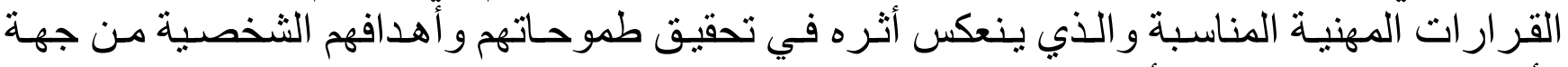
وأهداف المجتمع من جهة أخرى.

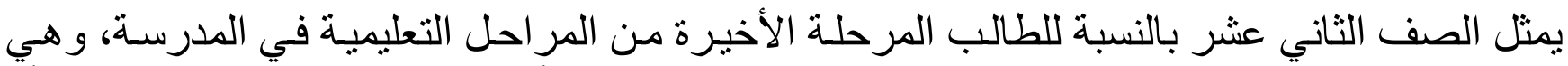

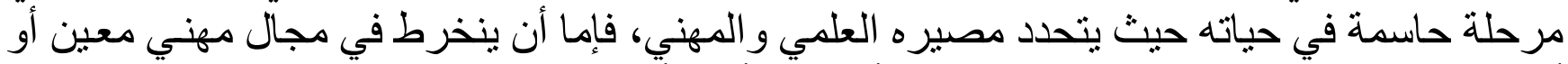

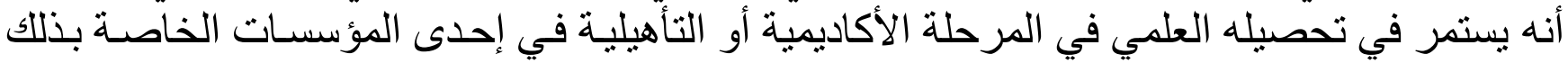

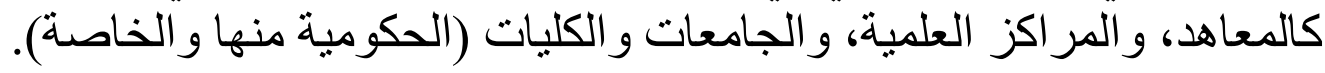
وباعتبار الصف الثاني عثر بالنسبة للطالب هي المرحلة الأخيرة و الحاسمة من المر احل الدر اسية في

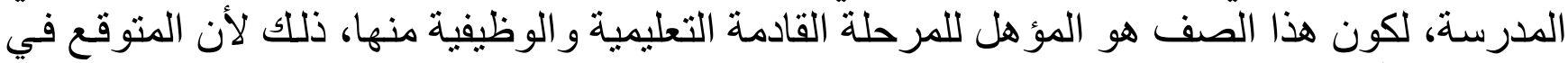

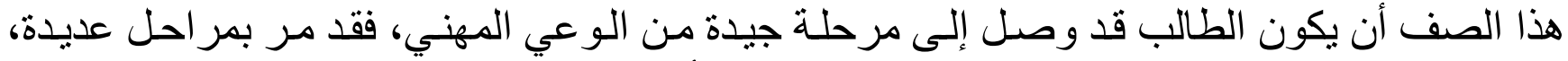

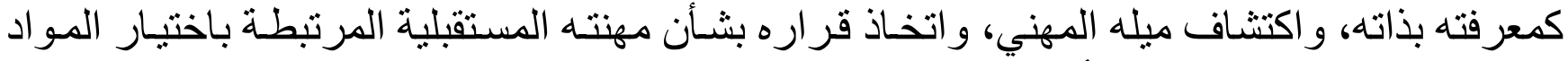

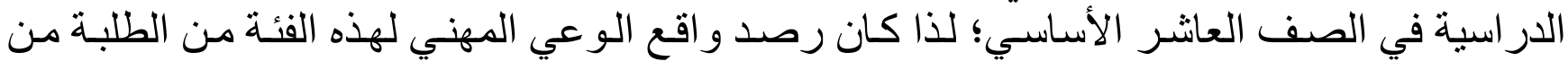


الأمور المهمـة التي تحمل في طياتهـا الكثير من المعـاني المرتبطـة بعمليـة التخطيط، وفيمـا إذا كـان اختيار الطلبة للمو اد الدر اسية المرتبطة بالتخصصات الأكاديمية مبنياً على أسس علمية فئية ووعي مهني.

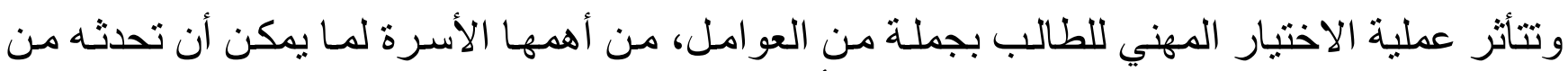

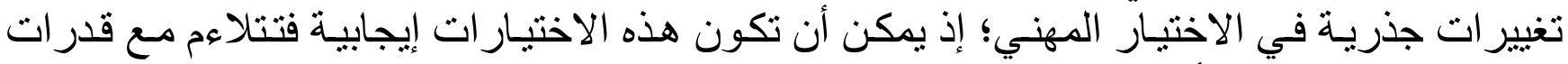

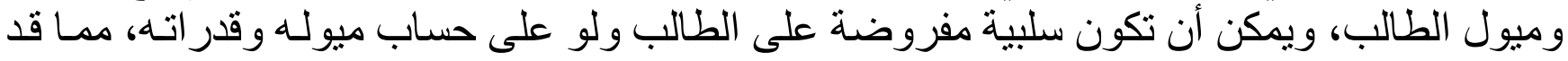

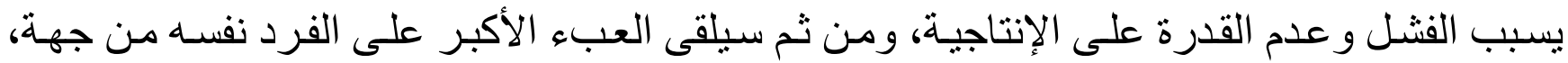

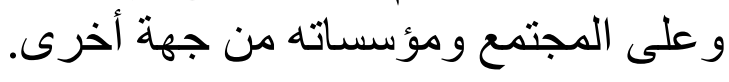

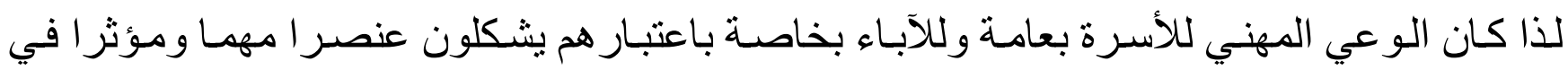

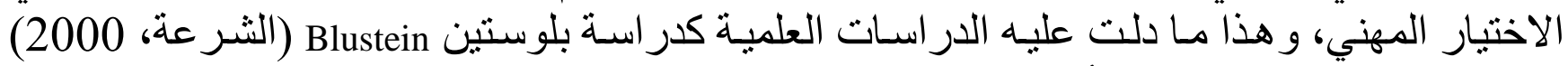

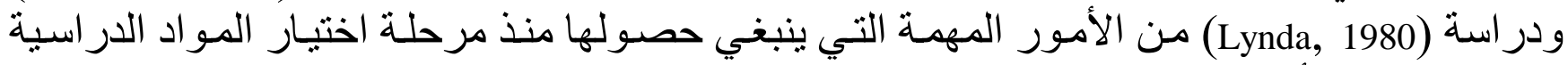

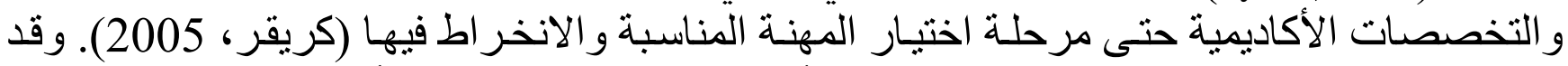

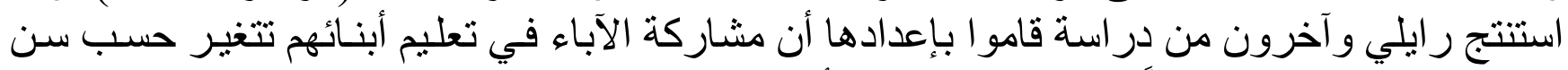

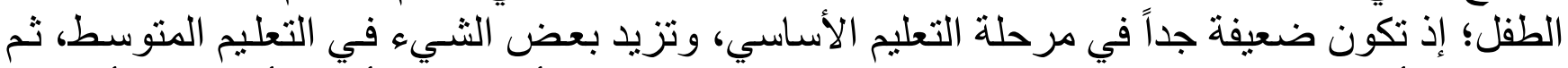

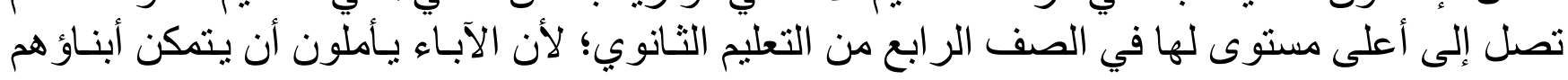

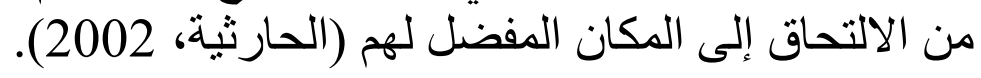

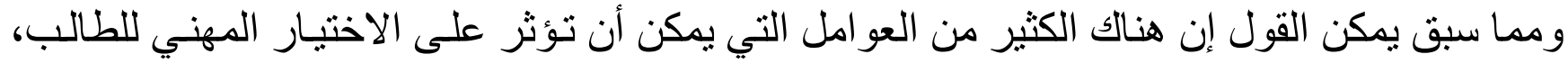

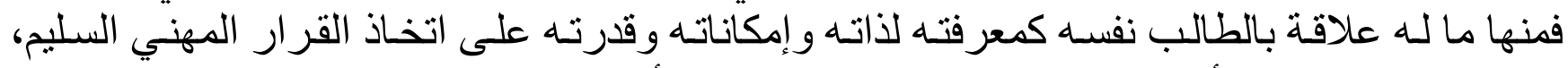

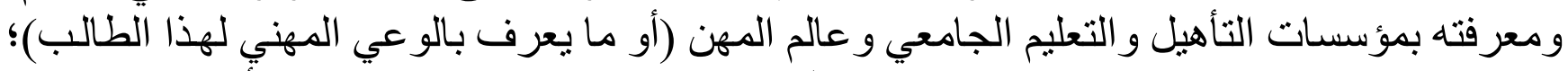

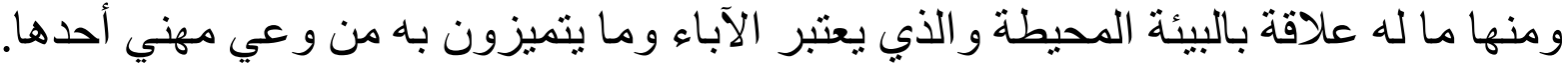
أهداف الدراسة:

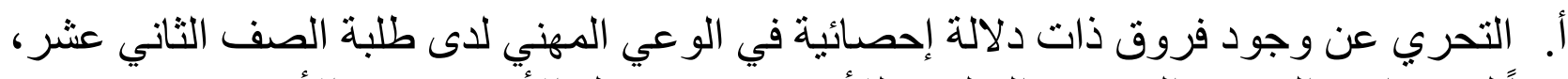

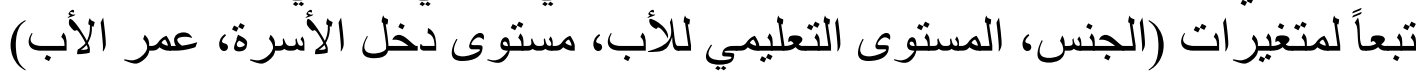

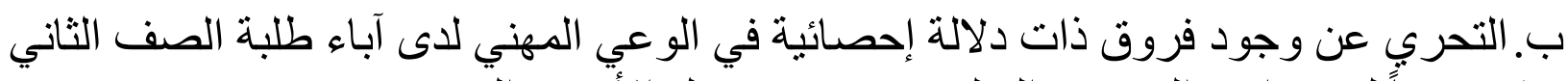

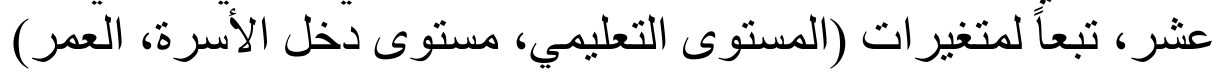

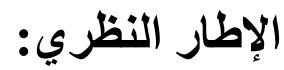

\section{التزبية المهنية في المرحلة الثانوية: المرية:}

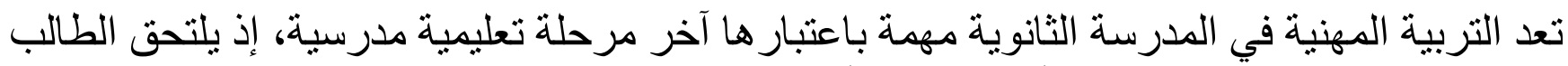

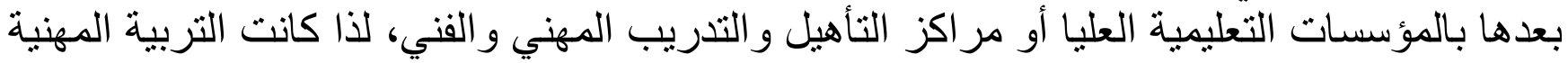

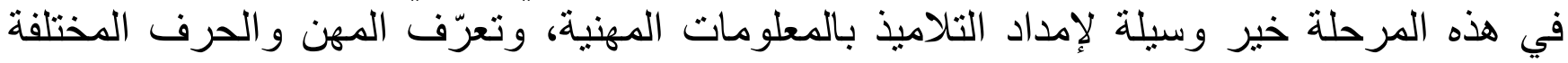
الموجودة في بيئتهم المحلية. ويعد (جس ديفز) أول من قدم مقرر الإنشاء ضمن مادة اللغة الإنجليزية، وقد تضمن مجموعة من 
الموضو عات منها: أساليب أو طرق الحصول على عمل، و التوافق المهني، ومشكلات العمال حديثي

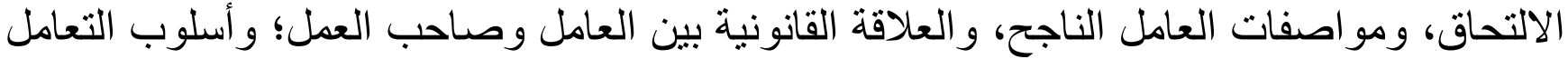

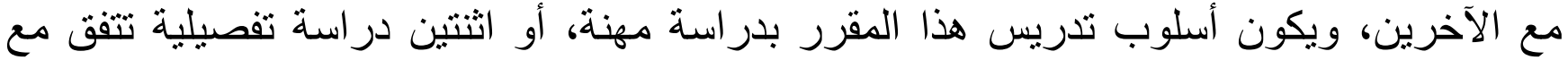
اهتمامات وقدرة الطالب؛ إذ يتضمن موضوع الآن الدر اسة التفصيلية مجموعة من العناصر منها: مقدمة

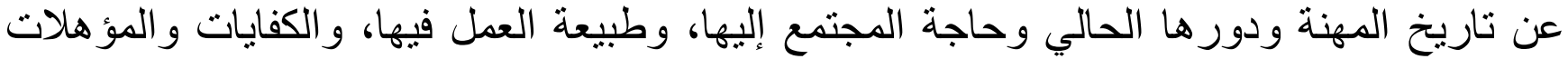
العلمية و الصحية و العقلية لهذه المهنة، و علاو اتها وترقياتها، و عدد العاملين بها(أبو عبطة، وطية 2002).

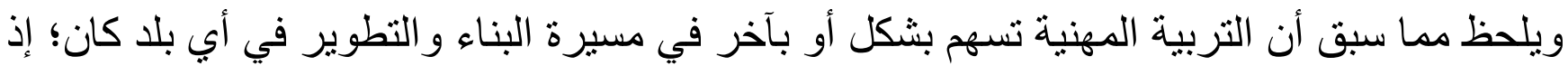

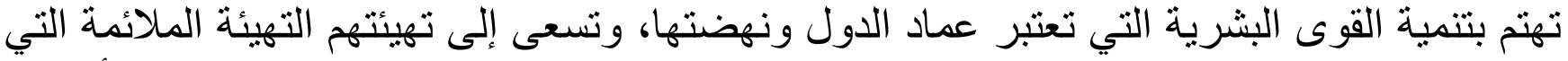
تساعدهم في الانخر اط في المجتمع بثقة ووعي و علم. وقد راعت اعت التربية المهنية في تحقيق أهدافها

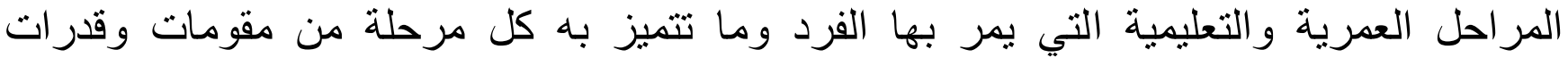

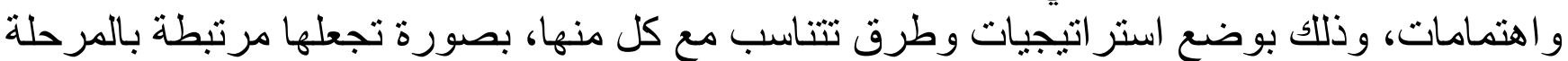
السابقة، ومهيأة للمرحلة اللاحقة.

وبذللك فإن اعتبار التربية المهنية وما تهدف إليه من تحقيق و غرس الوعي المهني من مقومات نهضية

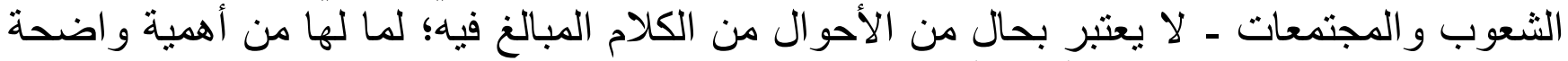

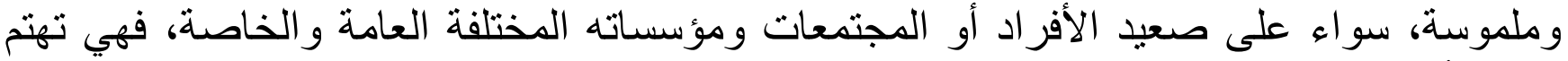
بيناء الأجيال على الصعيد الإنساني، وتهتم كذلك بالبناء الاقتصادي على التى الصعيد المادي.

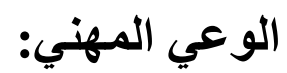

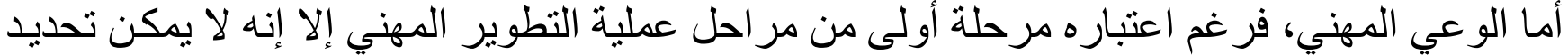

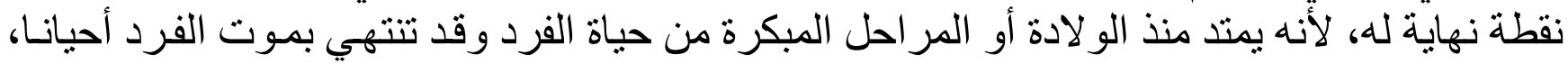

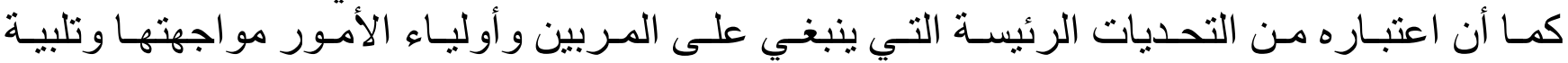

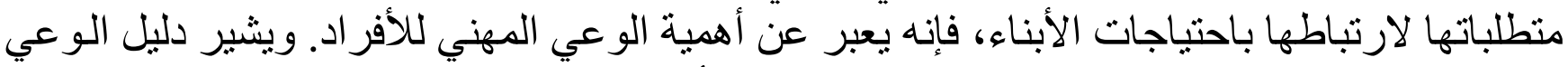

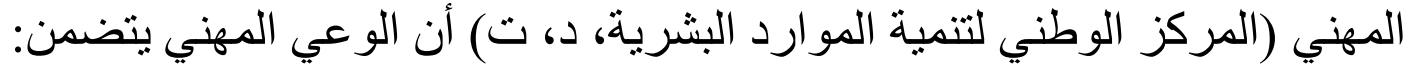
أ. التعرف على الميول و القدر ات و القيم ومر اعاتها في عملية الاختيار. ب. مهارة اتخاذ القرار ( الاستقلالية و المرونة).

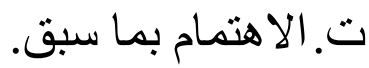

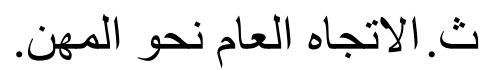

ويرى الباحث أن هذه المضامين للوعي المهني شملت جانبين مهمين هما: الوعي الذاتي بكل ما يتطلبه

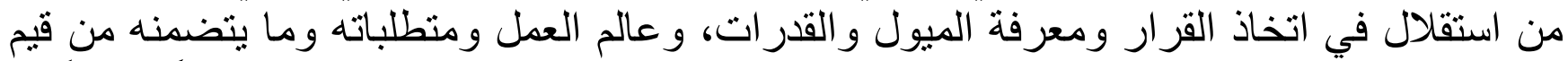

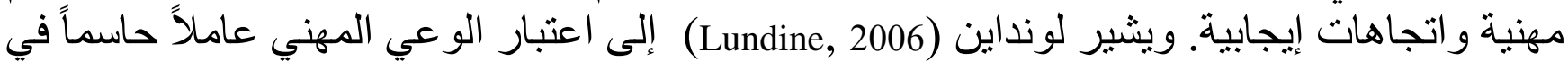

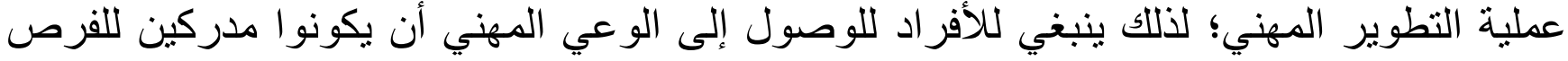

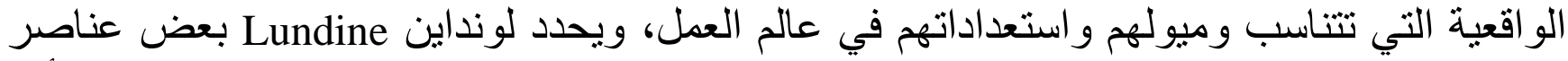

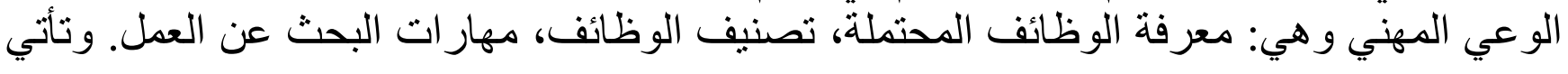


هذه النظرة تدعيما لما تم الإشارة إليه سابقاً، من أهمية الوعي المهني للأفر اد؛ بالإضافة إلى تحديده

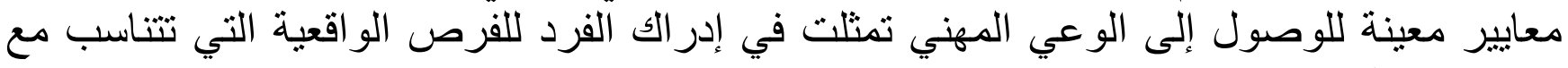
قدر اته وميوله.

ومن خلال ما سبق عرضها من مفاهيم متعددة للوعي المهني، وبـالرجوع إلى إلى الوعي بمفهومـه العـام -

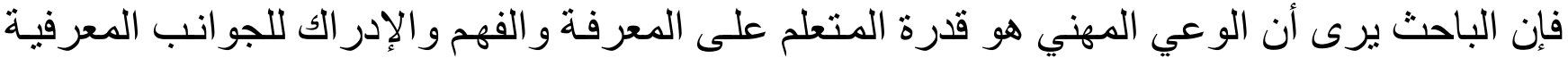

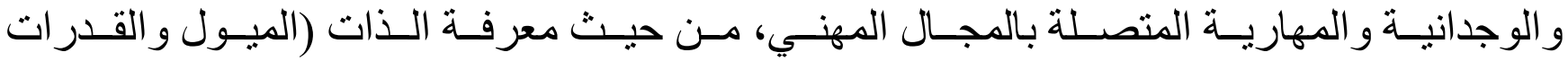
و المهار ات)، و عالم المهن و ونطلباتها، ومهارة اتخاذ القرار (الاستقلال و المرونة).

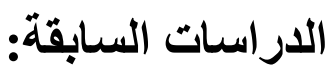

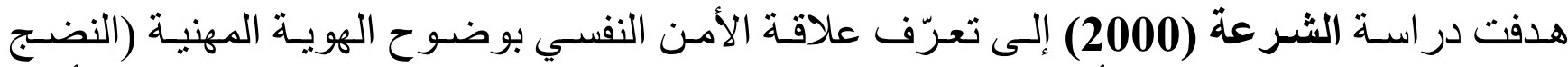

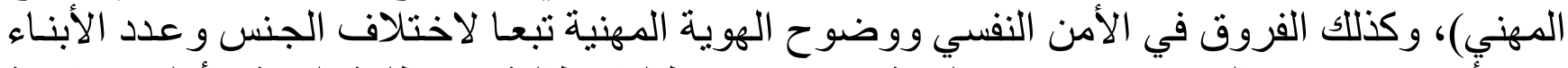

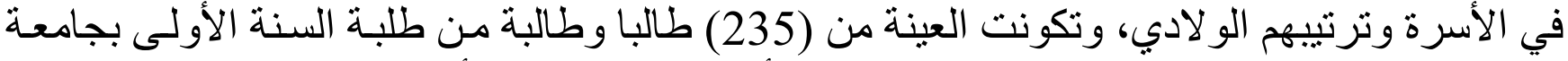

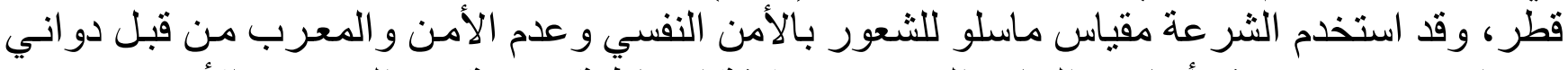

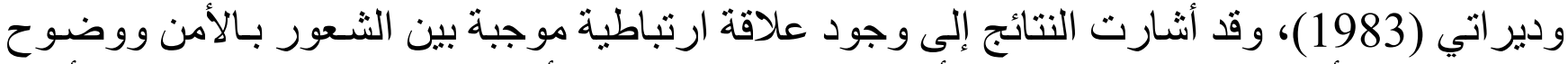

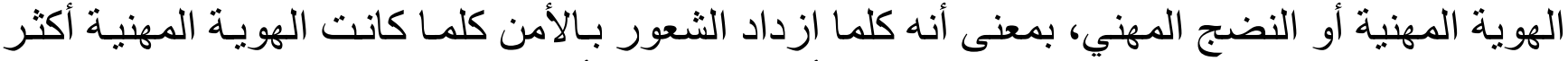

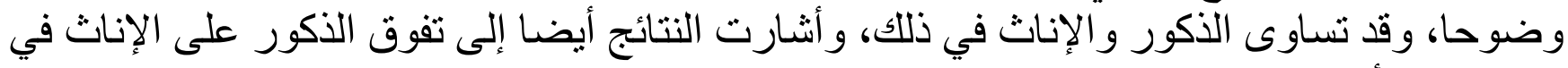

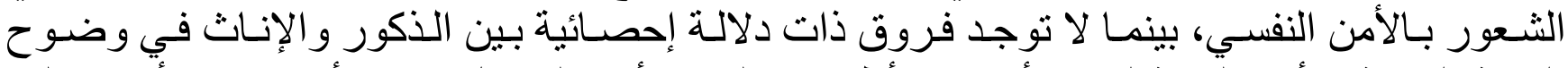

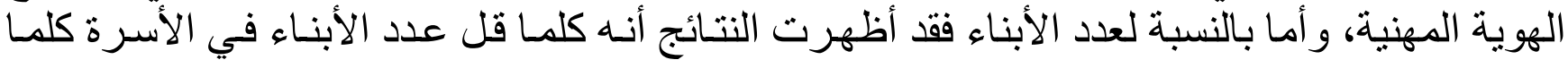

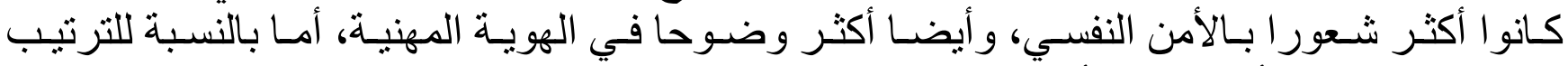

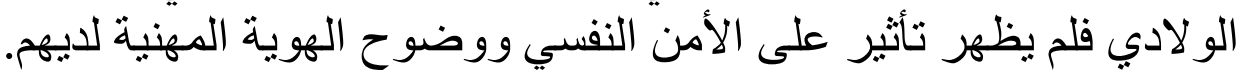

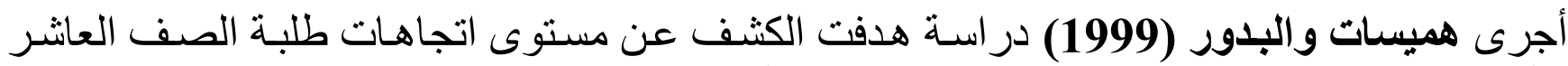

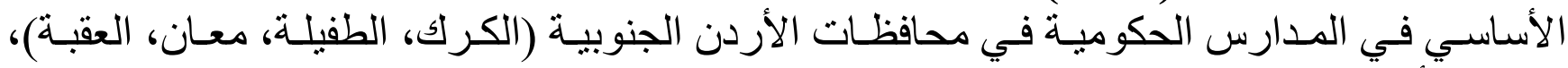

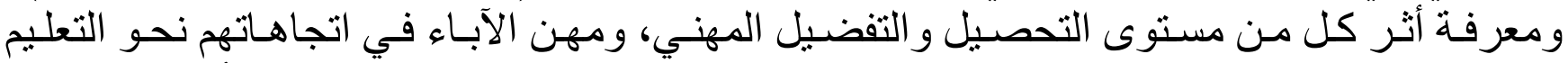

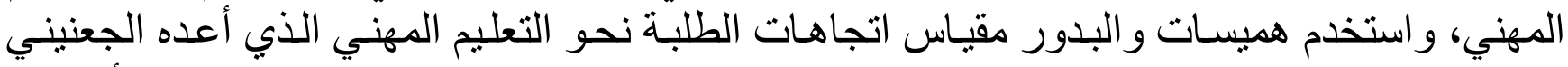

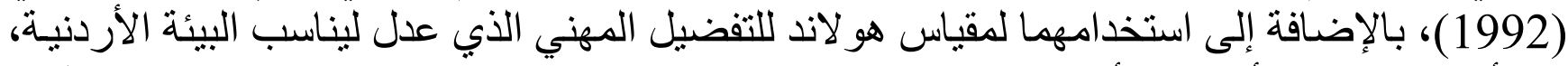

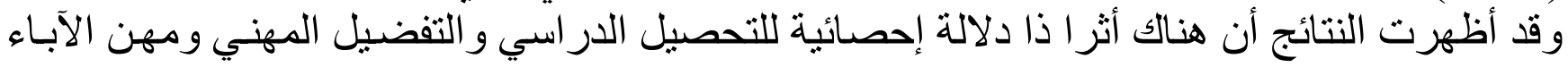
في اتجاهات الطلاب نحو التعليم المهني. أجرى البداينة والمجالي (1996) در اسة هدفت إلى معرفة اتجاه الحر الك الاجتماعي بين جيل الأجداد

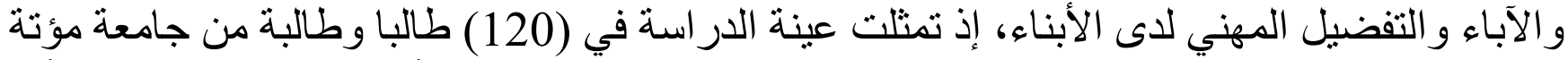

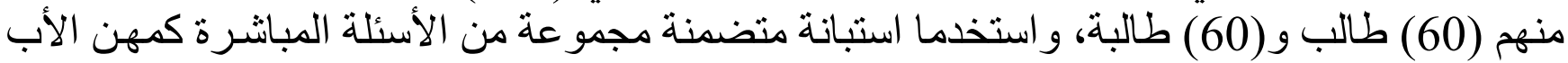

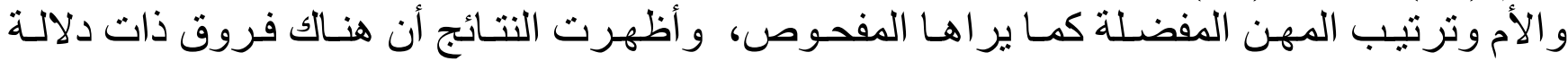

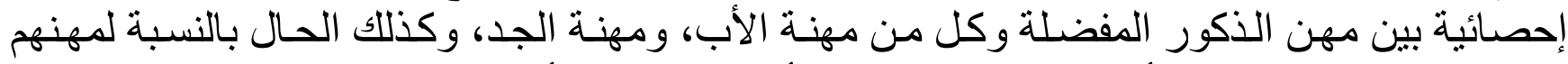

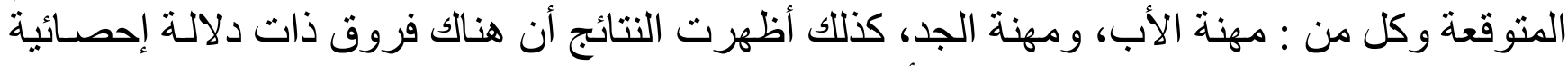
بين مهن الإناث المفضلة وكل من: مهنة الأم، ومهنة الجدة. 
منهجية الاراسة:

تتبع هذه الدر اسة منهج البحث الوصفي التحليلي،

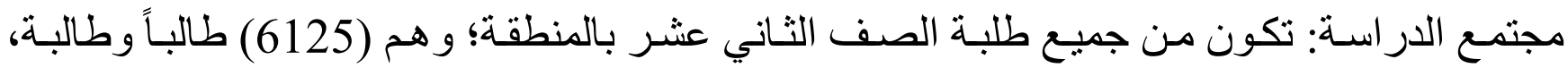
موز عين على (37) مدرسة في ست ون لايات،

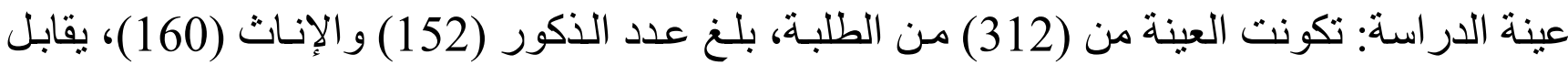
هؤلاء الطلبة آبائهم و عددهم (312).

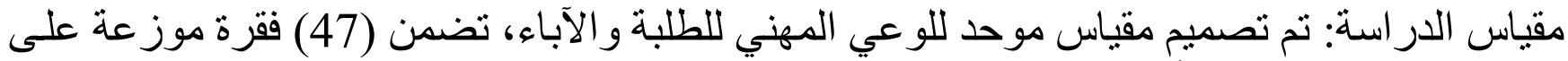

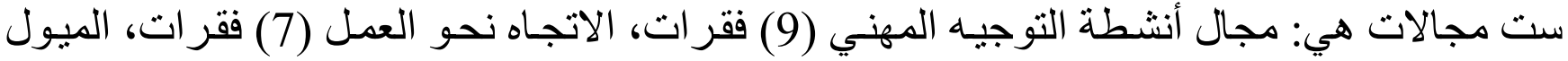
و القدر ات المهنية (7) فقرات، اتخاذ القرار المهني (9) فقر اته، الاتهمام المهني (8) فقرات، التخطيط المهني (7) فقرات.

المعالجة الإحصائية: تم استخدام التحليل الوصفي، اختبار (ت)، اختبار (One - Way ANOVA).

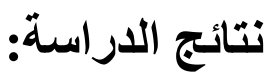

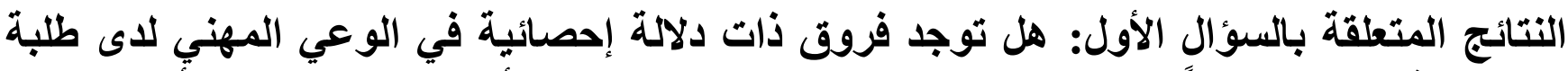

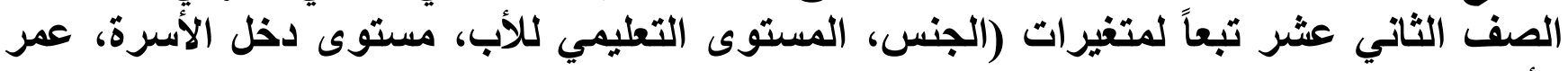
الابب) أولا: بالنسبة لمتغير الجنس (ذكور، إناث): لمعرفة الفروق في الوعي المهني لاى طلبة الصف الثاني عشر تبعاً لمتغير الجنس تم استخدام اختبار (1ndependent Samples T-test جدول (1) المتوسط الحسابي و الانحر اف المعياري وقيمة (T) لكل مجال من مجالات الوعي المهني وكلياً

\begin{tabular}{|c|c|c|c|c|c|c|}
\hline مستوي & قيمة t & المعياري & المستوسط & العدد & الثاني عشف & 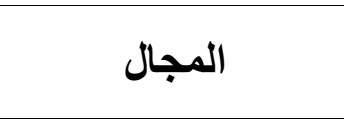 \\
\hline \multirow{2}{*}{0.011} & \multirow{2}{*}{2.573} & 0.474 & 3.56 & 152 & ذكور & \multirow{2}{*}{ المهني أنثطة } \\
\hline & & 0.505 & 3.70 & 160 & إناث & \\
\hline \multirow[b]{2}{*}{0.000} & \multirow[b]{2}{*}{5.602} & 0.383 & 3.93 & 152 & ذكور & \multirow{2}{*}{ العمل الاتجاه نحو } \\
\hline & & 0.377 & 4.17 & 160 & إناث & \\
\hline \multirow{2}{*}{0.274} & \multirow{2}{*}{1.097} & 0.380 & 3.67 & 152 & ذكور & \multirow{2}{*}{ و القدرات الميونية } \\
\hline & & 0.381 & 3.73 & 160 & إناث & \\
\hline \multirow{2}{*}{0.861} & \multirow{2}{*}{1.75} & 0.458 & 3.62 & 152 & ذكور & \multirow{2}{*}{ اتخاذ القرار المهني } \\
\hline & & 0.417 & 3.63 & 160 & إناث & \\
\hline \multirow{2}{*}{0.000} & \multirow{2}{*}{5.638} & 0.397 & 4.13 & 152 & ذكور & \multirow{2}{*}{ الاهتمام المهني } \\
\hline & & 0.3861 & 4.38 & 160 & إناث & \\
\hline 0.001 & 3.31 & 0.402 & 3.94 & 152 & ذكور & التخطيط المهني \\
\hline
\end{tabular}




\begin{tabular}{|c|c|c|c|c|c|c|}
\hline & & 0.422 & 4.10 & 160 & إناث & \\
\hline \multirow{2}{*}{0.000} & \multirow{2}{*}{5.036} & 0.252 & 3.81 & 152 & ذكور & \multirow{2}{*}{ الكلي } \\
\hline & & 0.244 & 3.95 & 160 & إناث & \\
\hline
\end{tabular}

يلحظ من الجدول (1) وجود فروق ذات دلالة إحصائية في الوعي المهني لدى طلبة الصف الثاني

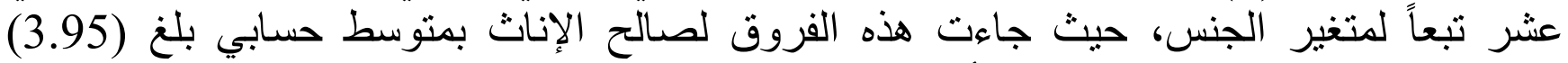

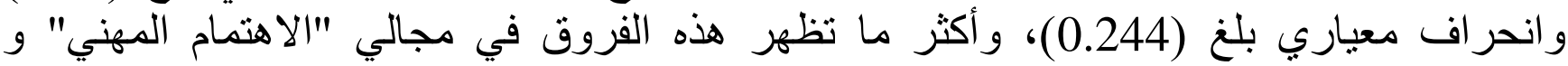
"الاتجاه نحو العمل" حيث بلغت قيمة (ت)، 5.638، على التو الي، وجاءت الفروق في هذين المجالين لصالح الإناث بمنوسط حسابي بلغ (5) (4.38،

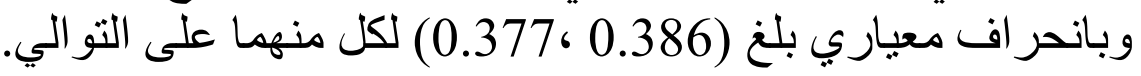

ثانيا: بالنسبة لمتغير المستوى التعليمي للأب لمعرفة الفروق في الوعي المهني لدى طلبة الصف الثاني عشر تبعاً لمتغير المستوى التعليمي للأب،

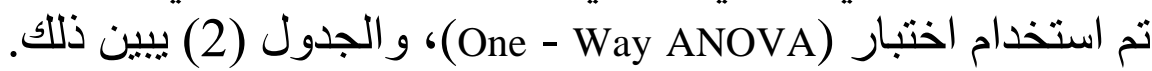

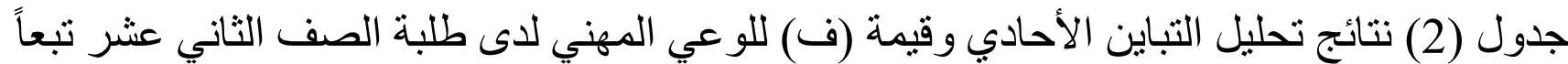

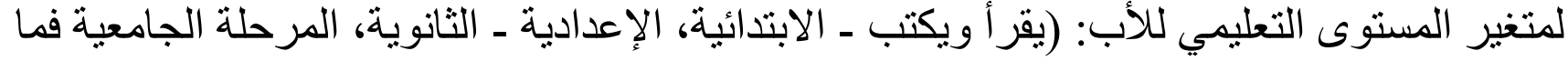

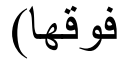

\begin{tabular}{|c|c|c|c|c|c|}
\hline مستوى الدلالة & قيمة ف & المتوبعات & الدرجة & المربعوت & مصدر التباين \\
\hline \multirow[t]{3}{*}{0.632} & 0.460 & 3.066 & 2 & 6.133 & بين المجمو عات \\
\hline & & 6.673 & 309 & 20.619 & داخل المجمو عات \\
\hline & & & 311 & 20.681 & الكلي \\
\hline
\end{tabular}

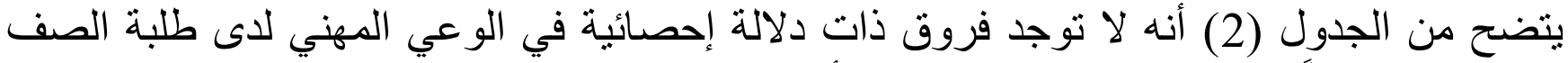

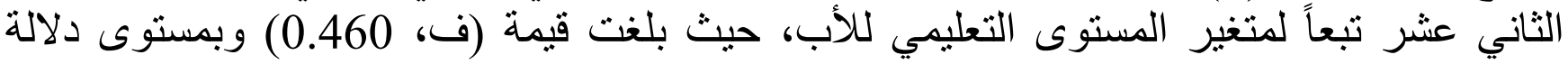
.$(0.632)$

ثالثا: بالنسبة لمتغير مستوى دخل الأسرة لمعرفة الفروق في الوعي المهني لدى طلبة الصف الثاني عشر تبعاً لمتغير مستوى دخل الأسرة، تم

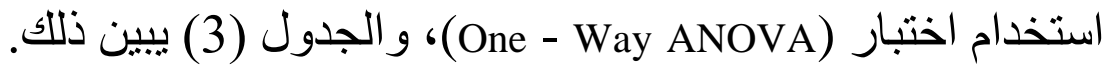

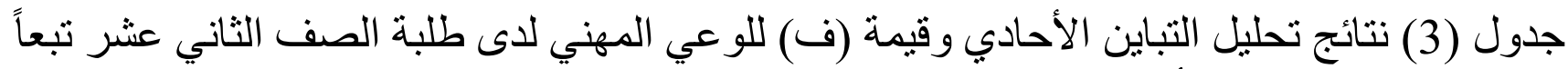

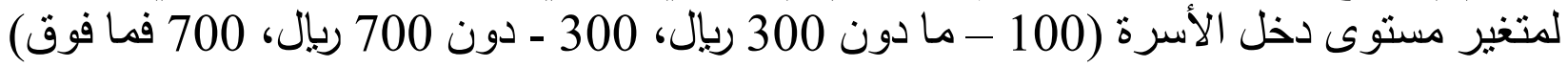

\begin{tabular}{|c|c|c|c|c|c|}
\hline مستوي الدلاية & قيمة ف & متوسط & الحرجية & المجبعوع & مصدر التباين \\
\hline
\end{tabular}


IJASOS- International E-Journal of Advances in Social Sciences, Vol. VI, Issue 17, August 2020

\begin{tabular}{|l|c|c|c|c|c|}
\hline 0.831 & 0.186 & 1.241 & 2 & 2.483 & بين المجموعات \\
\hline & & 6.685 & 309 & 20.656 & داخل المجمو عات \\
\hline & & & 311 & 20.681 & الكلي \\
\hline
\end{tabular}

يتضح من الجدول (3) أنه لا توجد فروق ذات دلالة إحصائية في الوعي المهني لاى طلبة الصف

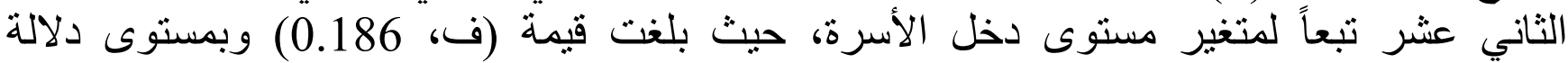

.0.831)

\section{رابعا: بالنسبة لمتغير عمر الأب}

لمعرفة الفروق في الوعي المهني لدى طلبة الصف الثاني عشر تبعاً لمتغير عمر الأب، تم استخدام اختبار (One - Way ANOVA)، والجدوف الون (4) (4) يبين ذلك.

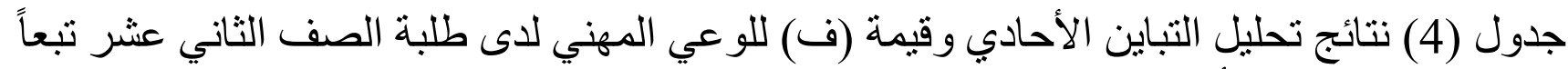
لمتغير عمر الأب (30 - ما دون 40 سنة، 40 - ما دون 50 سنة التة، 50 سنة فما فوق)

\begin{tabular}{|c|c|c|c|c|c|}
\hline مستوى الدلاية & قيمة ف & متوسط المربعات & الحرجة & المربعوات & مصدر التباين \\
\hline \multirow[t]{3}{*}{0.150} & 1.910 & 0.126 & 2 & 0.253 & بين المجمو عات \\
\hline & & 6.611 & 309 & 20.428 & داخل المجمو عات \\
\hline & & & 311 & 20.681 & الكلي \\
\hline
\end{tabular}

يتضح من الجدول (4) أنه لا توجد فروق ذات دلالة إحصائية في الوعي المهني لاى طلبة الصف

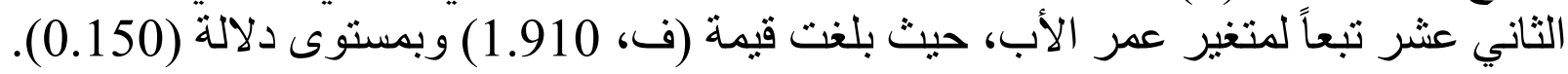

مناقشة نتيجة السؤال الأول:

أولا: متغيز الجنس مانس

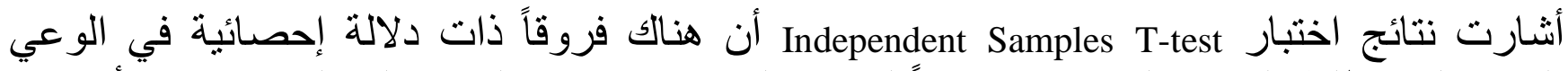

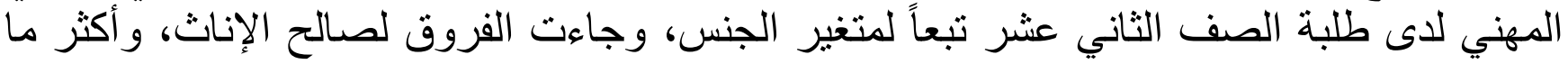

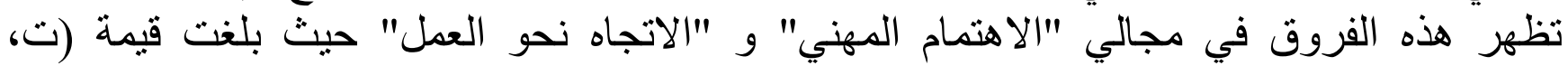

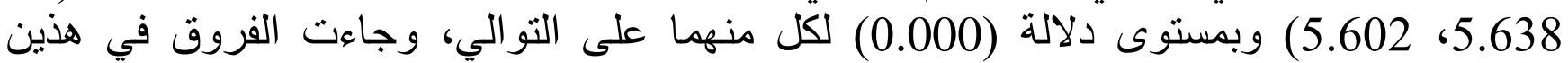

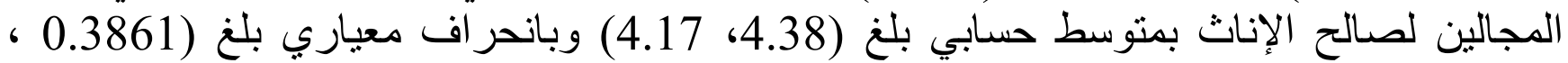

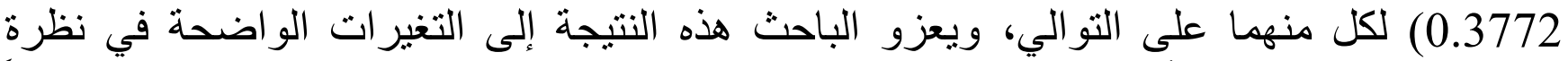

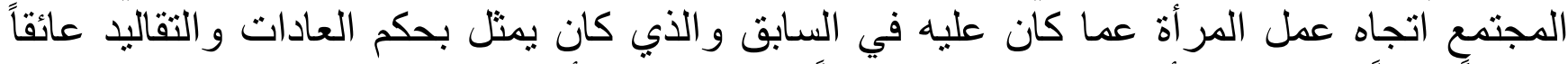

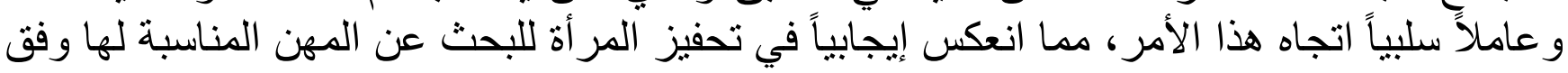


ميولها واستعداداتها حالها في ذلك كحال الرجل، وبالتالي أثز ذلك على اتجاهات الطالبات في

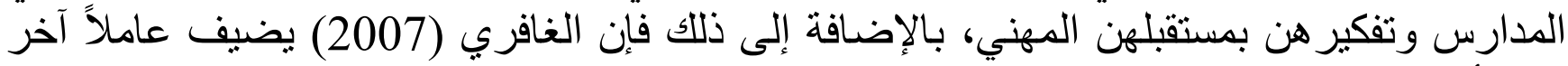
و هو أن تفوق الإناث على الذكور في الوعي المهني قد يكون سببه تفوقهن عليهم في التحصيل كما

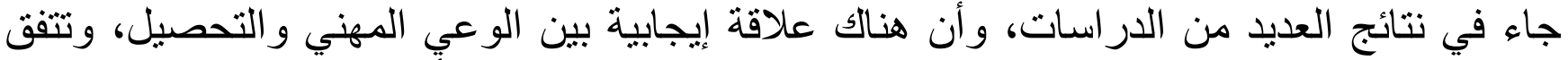

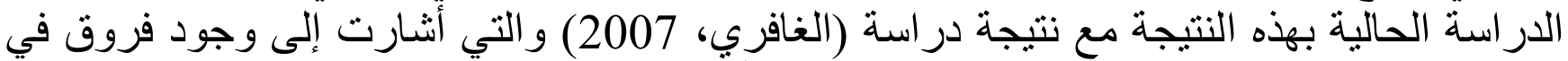

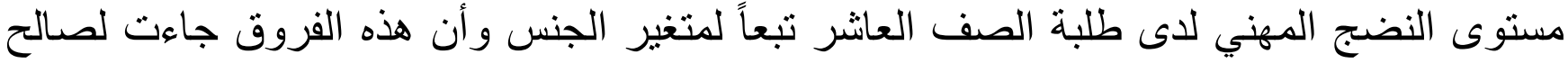

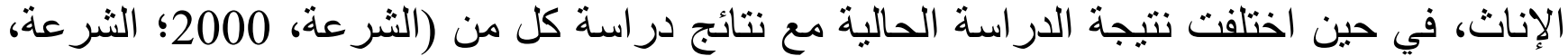

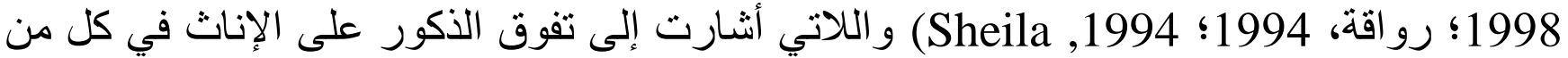

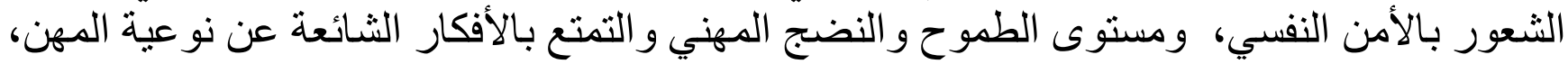

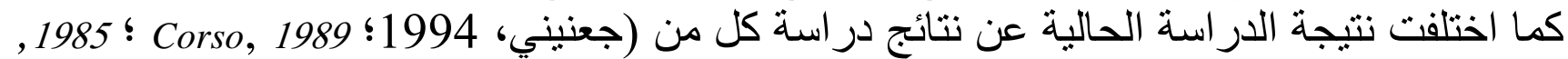

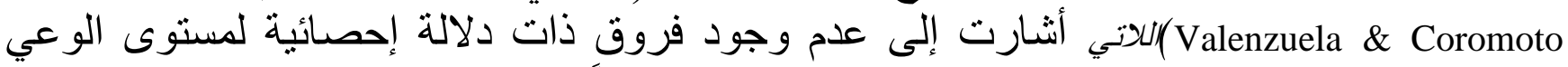
المهني و الاتجاه نحو التعليم المهني و التصور اتثي نحو المهن تبعاً لمتغير الجنس. ثانيا: متغير المستوى التعليمي لثلاب

أثـارت نتائج اختبار (One - Way ANOVA) إلى عدم وجود فروق ذات دلاللة إحصـائية في الوعي

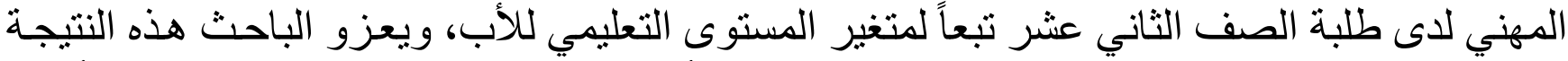

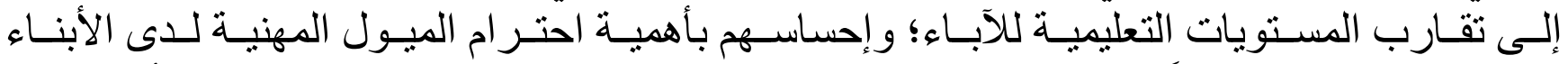

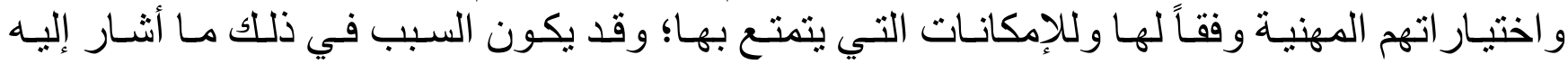

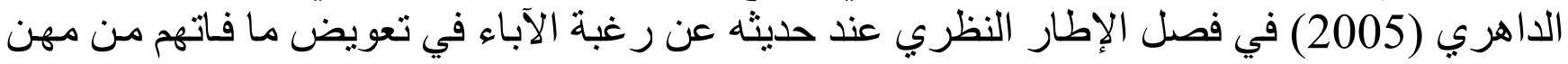

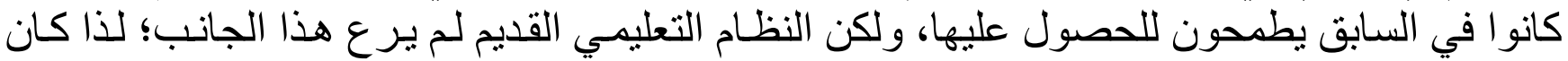

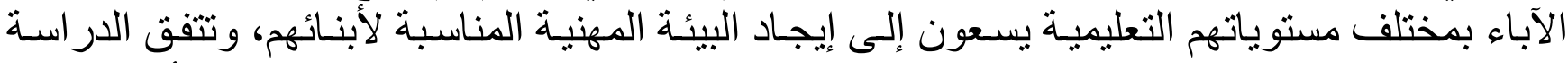

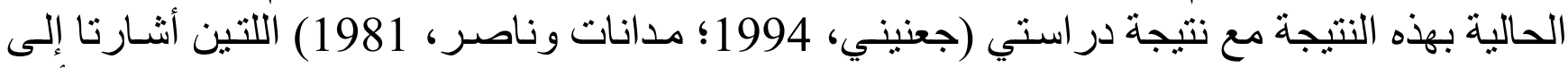

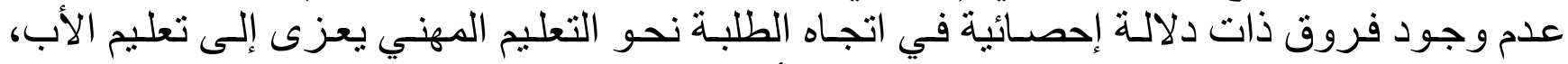

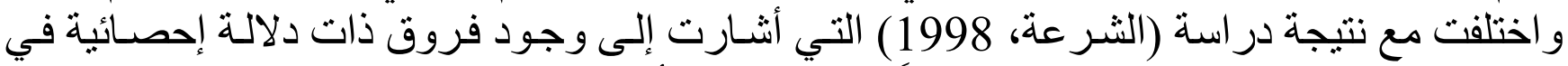
مستوى طموح الطلبة ونضجهم المهني تبعاً لمتغير تعليم الأب.

ثالثا: متغير مستوى دخل الأسرة

أشارت نتائج اختبار (One - Way ANOVA) إلى عدم وجود فروق ذات دلالة إحصائية في الوعي لإئي

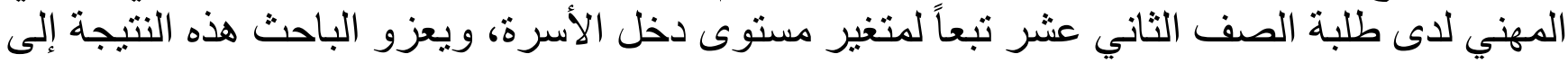

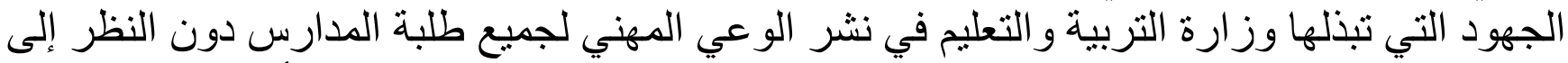

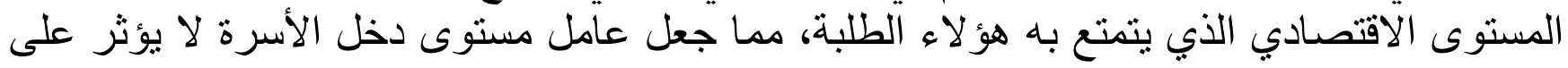

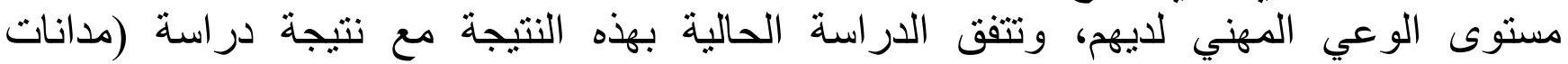
وناصر، 1981) و التي أثنارت إلى عدم وجود فروق ذات دلى دلالة في اتجاهات الطلبة نحو التعليم المهني

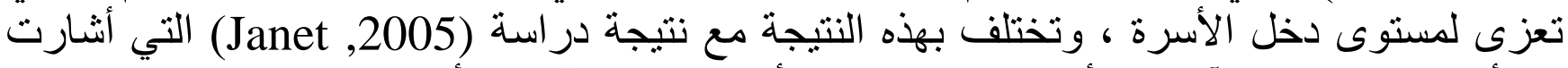

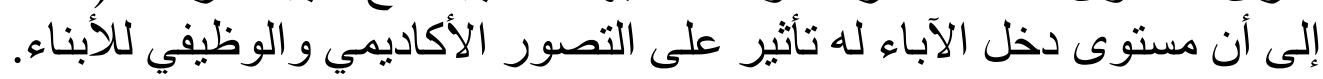


رابعا: متغير عمر الأب

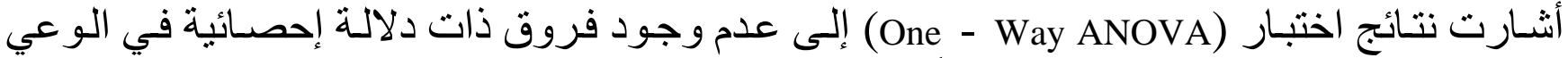

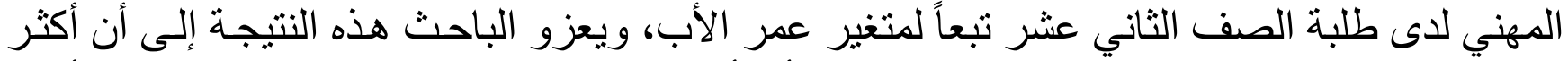

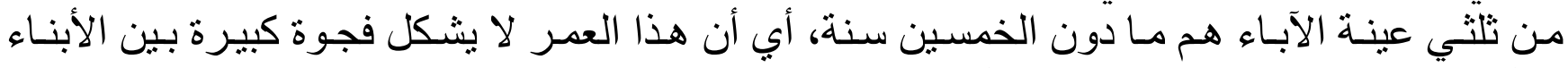

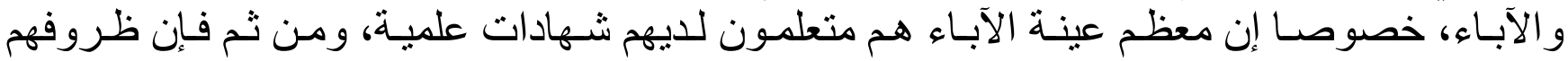

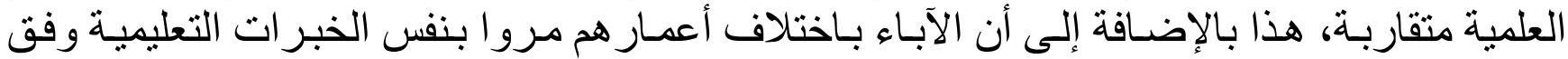

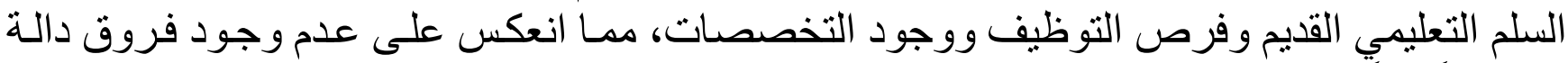
إحصائياً تبعاً لمتغير عمر الآباء.

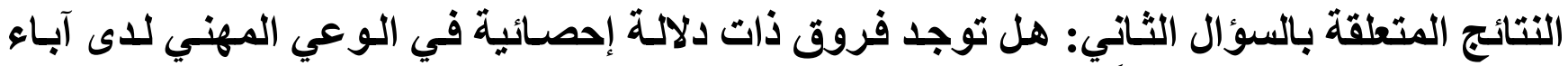

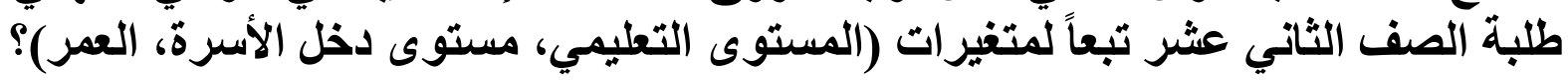

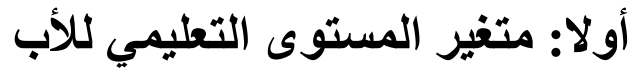

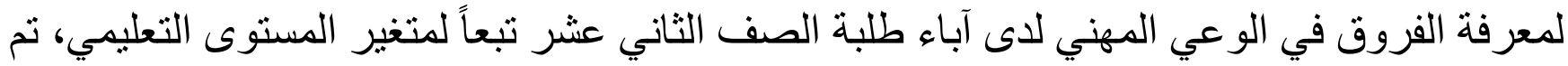

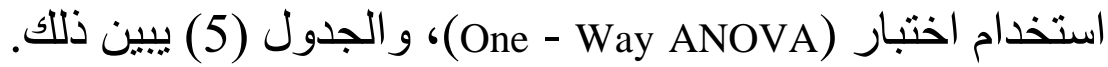

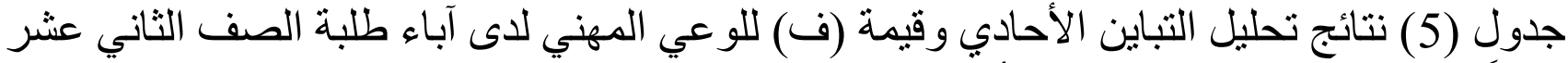

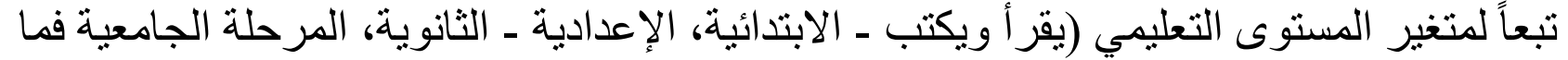

فوقها)

\begin{tabular}{|c|c|c|c|c|c|}
\hline اللالتة & قيمة ف & المربعات & الدرجية & المربعوت & مصدر التباين \\
\hline \multirow[t]{3}{*}{0.148} & 1.920 & 0.141 & 2 & 0.283 & بين المجمو عات \\
\hline & & 7.368 & 309 & 22.766 & داخل المجمو عات \\
\hline & & & 311 & 23.049 & الكلي \\
\hline
\end{tabular}

يتضح من الجدول (5) أنه لا توجد فروق ذات دلالة إحصائية في الوعي المهني لدى آباء طلبة الصف

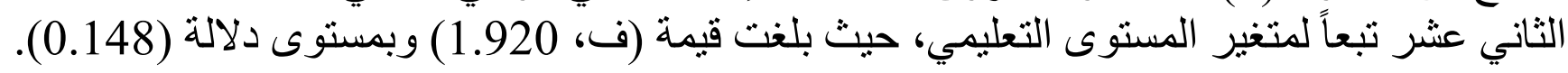
ثانيا: متغير مستوى دخل الأسرة لمعرفة الفروق في الوعي المهني لدى آباء طلبة الصف الثاني عشر تبعاً لمتغير مستوى دخل الأسرة،

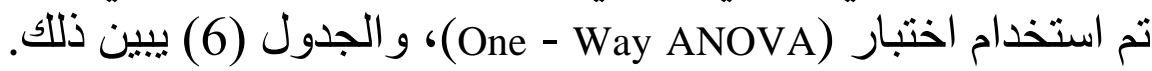

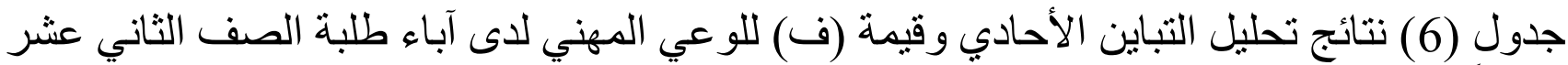

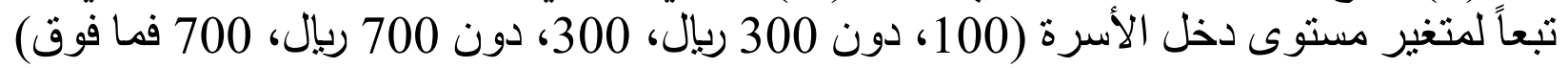


IJASOS- International E-Journal of Advances in Social Sciences, Vol. VI, Issue 17, August 2020

\begin{tabular}{|c|c|c|c|c|c|}
\hline مستوى الدلاية & قيمة ف & متوسطات & الحرية & المربعوع & مصدر التباين \\
\hline \multirow[t]{3}{*}{0.509} & 0.678 & 5.033 & 2 & 0.101 & بين المجمو عات \\
\hline & & 7.427 & 309 & 22.948 & داخل المجمو عات \\
\hline & & & 311 & 23.049 & الكلي \\
\hline
\end{tabular}

يتضح من الجدول (6) أنه لا نوجد فروق ذات دلالة إحصائية في الوعي المهني لدى آباء طلبة الصف

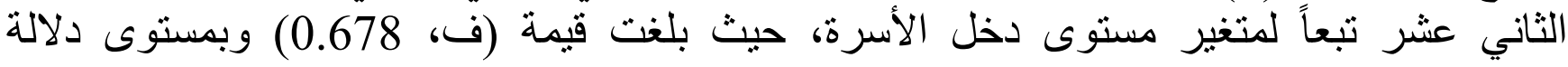

.(0.509)

ثالثا: متغير عمر الأب

لمعرفة الفروق في الوعي المهني لدى آباء طلبة الصف الثاني عشر تبعاً لمتغير العمر، تم استخدام

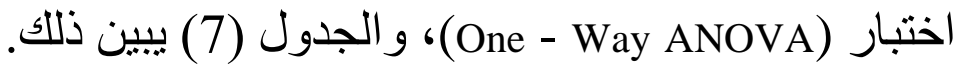

جدول (7) نتائج تحليل التباين الأحادي وقيمة (ف) للو عي المهني لدى آباء طلبة الصف الثفان الثاني عشر

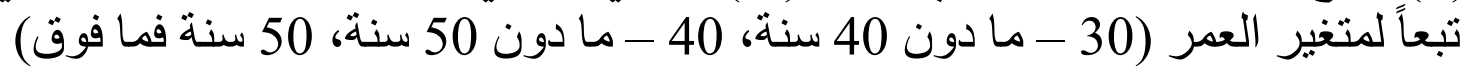

\begin{tabular}{|c|c|c|c|c|c|}
\hline مستوى الدلاكة & قيمة ف & المربعات & الحرجية & المربعوات & مصدر التباين \\
\hline \multirow[t]{3}{*}{0.482} & 0.732 & 5.437 & 2 & 0.109 & بين المجمو عات \\
\hline & & 7.424 & 309 & 22.940 & داخل المجمو عات \\
\hline & & & 311 & 23.049 & الكلي \\
\hline
\end{tabular}

يتضح من الجدول (7) أنه لا نوجد فروق ذات دلالة إحصائية في الوعي المهني لدى آباء طلبة الصف

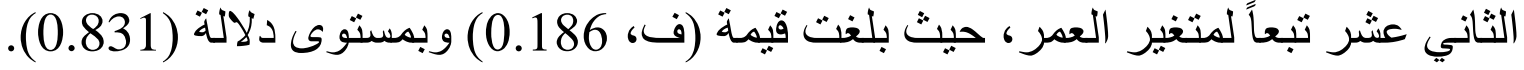
مناقشة نتائج السؤال الثاني: أولا: بالنسبة لمتغير المستوى التعليمي

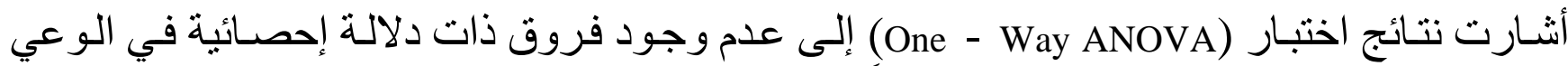

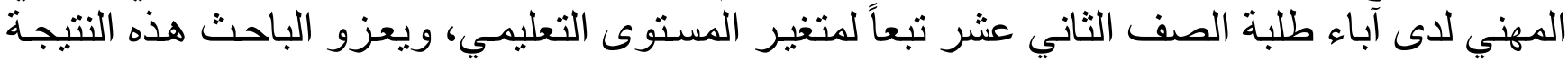

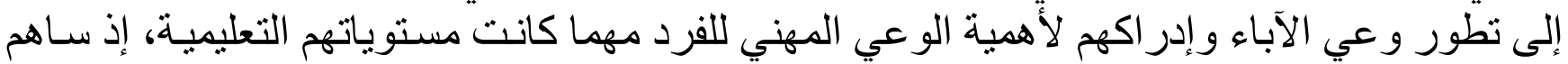

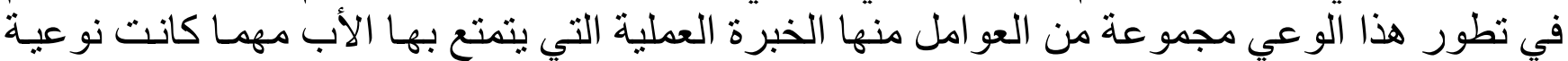

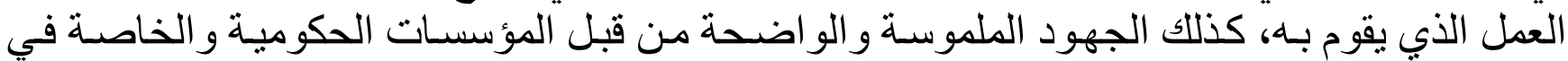

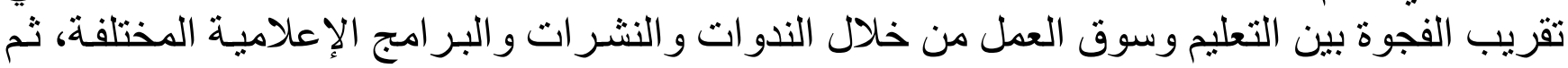




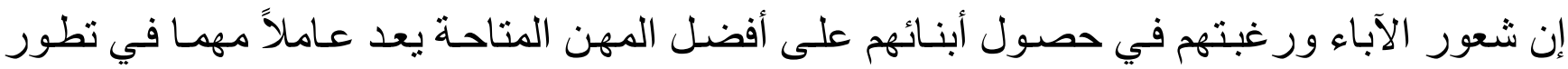

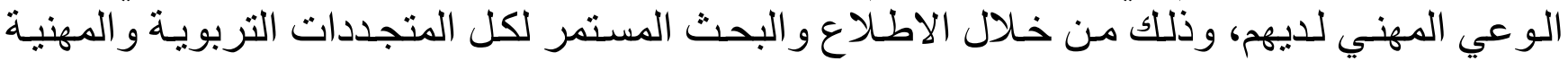
و التغير ات الحاصلة في سوق العمل.

\section{ثناتيا: بالنسبة لمتغير مستوى دخل الأسرة}

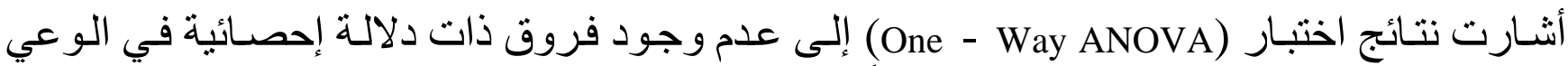

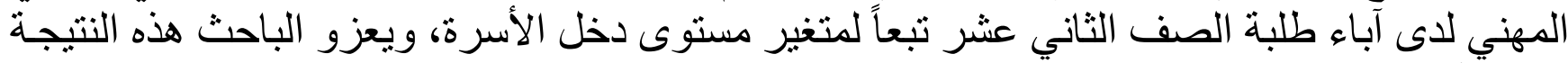

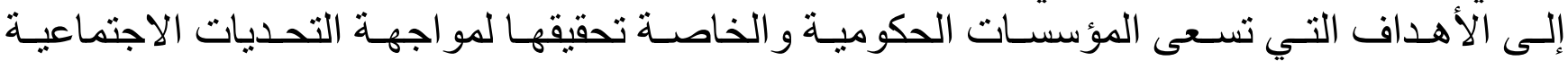

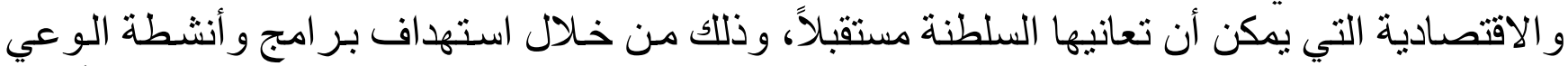

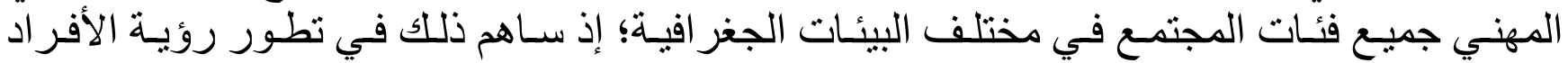

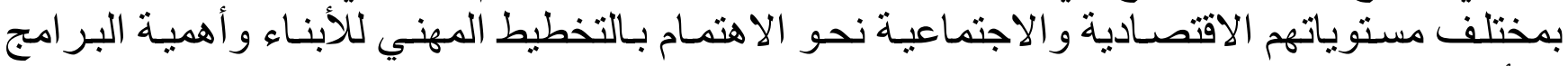
و الأنشطة التي تساعد على ذلك.

ثالثا: بالنسبة لمتغير العمر

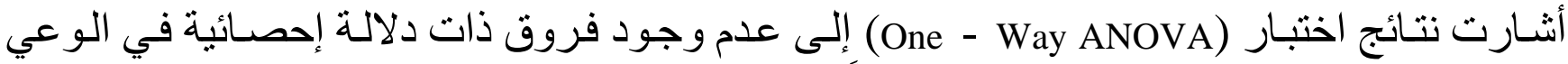

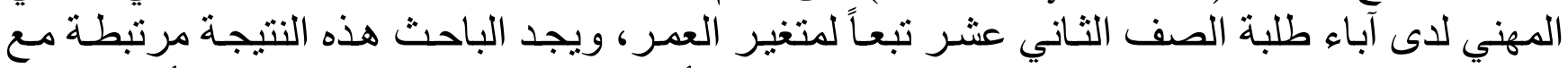

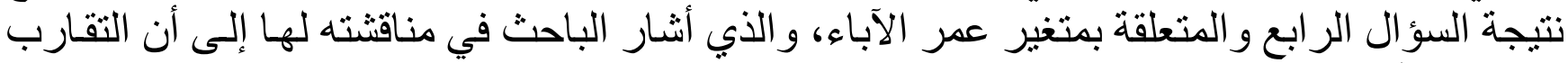

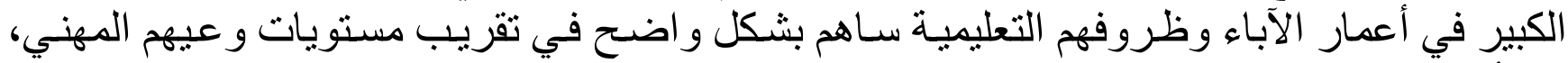

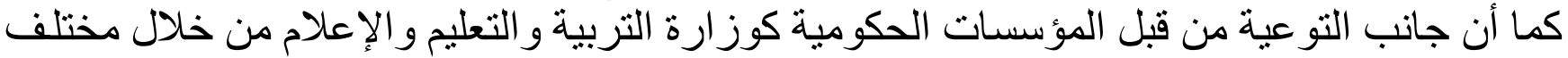

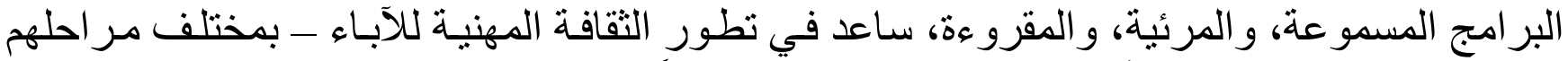

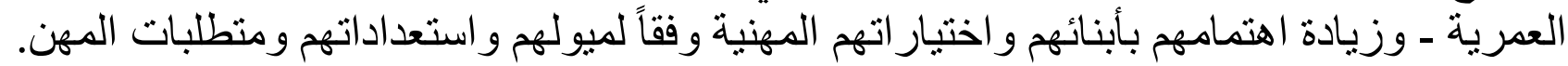

أهم نتائج الدراسة:

أ. وجود فروق ذات دلالة إحصائية في الوعي المهني لدى طلبة الصف الثاني عشر تبعاً لمتغير

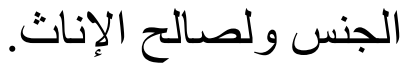

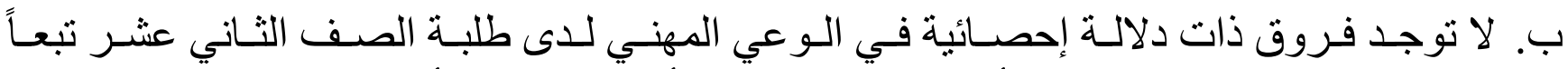

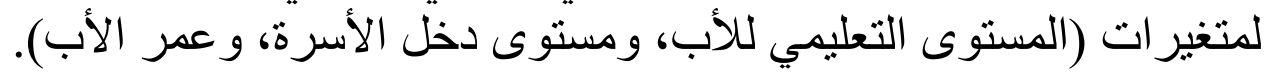

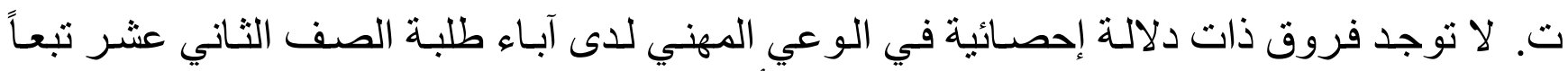

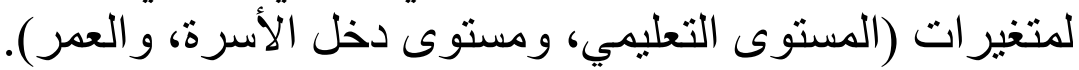

قائمة المراجع: أبو عيطة، سهام ححمد (2002). مبادئ الإرشاد النفسي. ط2، عمان، دار الفكر. 
البداينـة، ذيـاب و المجـالي، فـايز (1996). الحر الك الاجتمـاعي بـين الأجيـال و التفضـيل المهنـي بـين

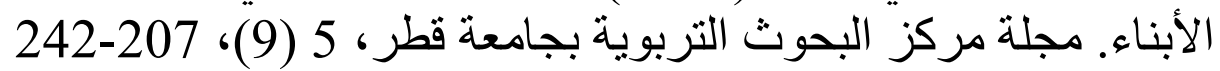

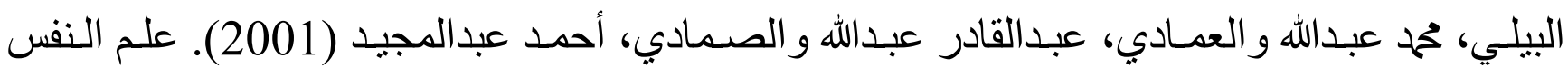
التربوي وتطبيقاته. ط3، الكويت، مكتبة عادية الفلاح.

جعنيني، نعيم (1994). اتجاهات طلبة الصف العانشر الأساسي في المدارس الحكوميـة في لو اء مأدبـا

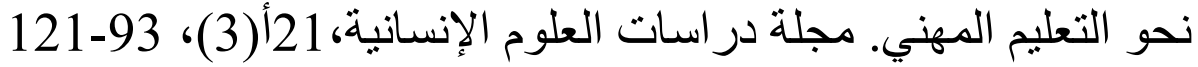

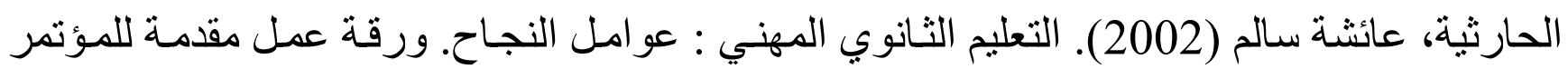

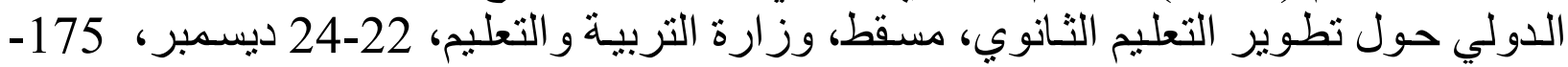

الداهري، صالح حسن (2005). سيكولوجية التوجيه المهني ونظرياته. ط1، عمان، دار وائل.

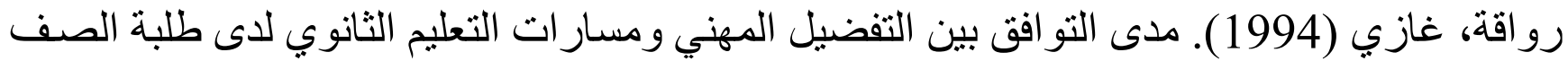

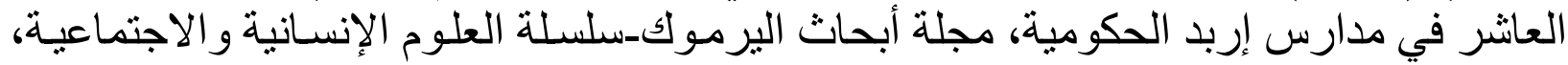

$$
.95-75 \text { ، } 95 \text { (2)11 }
$$

الثرعة، حسين (1998). علاقة مستوى الطموح و الجنس بالنضـج المهني لدى طلبـة الصف الـف الثاني

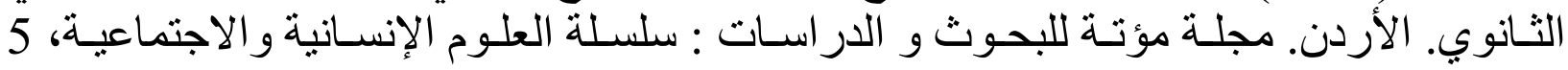

$$
\text { .33-11، (13) }
$$

الثـر عة، حسـين سـالم (2000)، الأمـن النفسـي و علاقتـه بوضـوح الهويـة المهنيـة، مؤتـة للار اسـات

$$
\text { و البحوث، } 15 \text { (3)، 157- } 205 .
$$

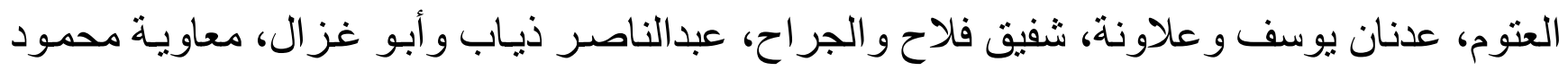
(2005). علم النفس التربوي (النظرية والتطبيق). عمان، دان، دار المسيرة.

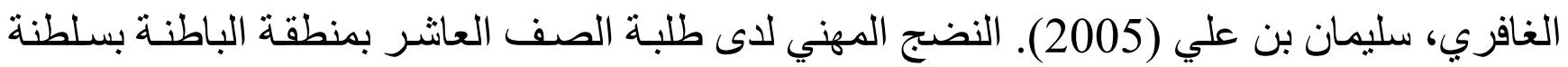

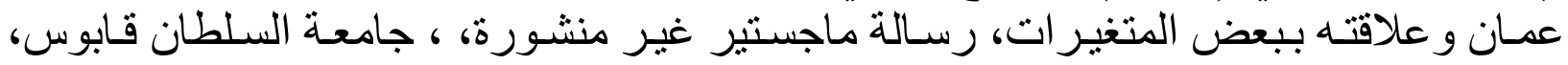
سلطنة عمان.

كريقر، ليندا سلفرمان (2005). إرشاد المو هوبين والمتفوقين. (ترجمة: سعيد حسني العزة)، عمـان، دار الثقافة.

المركز الوطني لتتمية الموارد البشرية (د، ت)، دليل تطوير الوعي المهني، صندوق الملك عبدالله

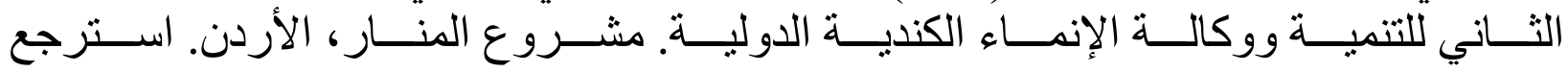

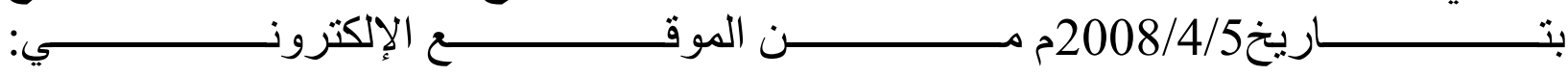
http://www.almanar.jo/AlManarWeb/Default.aspx?tabid=122\&lang=ar-JO

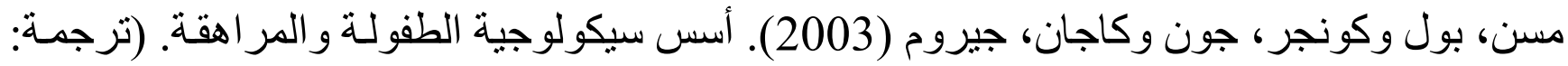

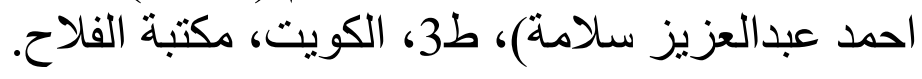




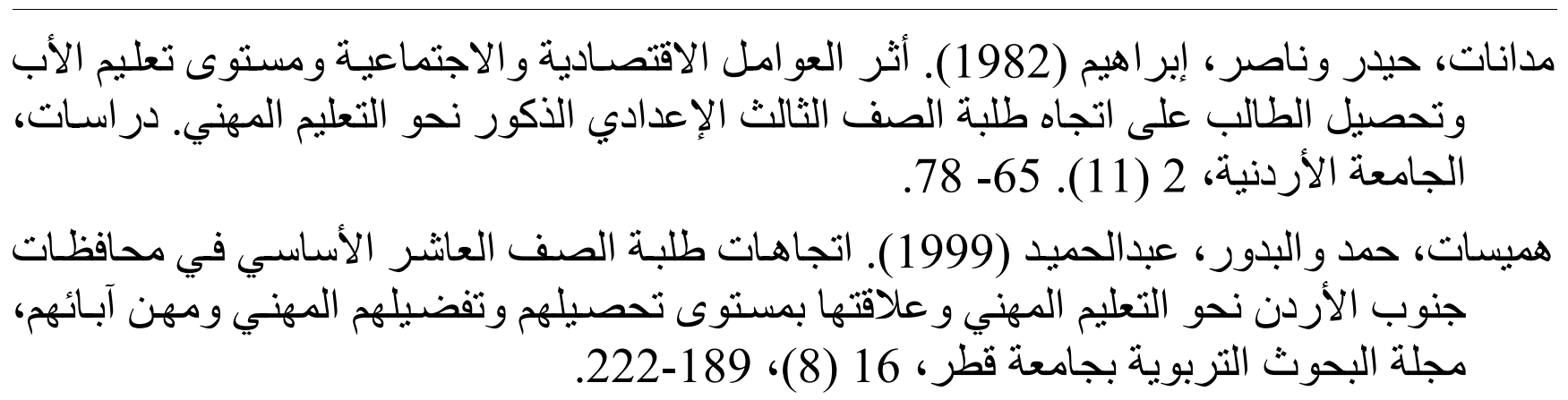

\section{ARABIC REFERENCES IN ROMAN ALPHABET}

Abu Eitat, Saham Muhamad (2002). Mabadi Al'iirshad Alnafsi. Ta2, Eumaan, Dar Alfikr.

Albdaynat, Dhiaab Walmajali, Fayiz (1996). Alhurak Alaijtimaeia Bayn Al'ajyal Waltafdil Almahnii Bayn Al'abna'. Majalat Markaz Albihwth Altarbawiat Bijamieat Qatar, 5 (9), 207-242

Albayli, Muhamad Eabdallh Waleimadi, Eabdalqadr Eabdallah Walsamadi, 'Ahmad Eibdialmjid (2001). Eilm Alnafs Altarbwi Watatbiaqatih. T3, Alkuayt, Maktabat Alfalah.

Jaenini, Naeim (1994). Aitijahat Tlbt Alsafi Aleashir Al'asasii Fi Almadaris Alhukumiat Fi Liwa' Madabaan Nahw Altaelim Almahnii. Majalat Dirasat Aleulum Al'iinsaniat,21a(3), 93-121

Alharthiat, Eayishat Salim (2002). Altaelim Althaanawiu Almahniu : Eawamil Alnajah. Waraqat Eamal Muqadimat Lilmutamar Alduwalii Hawl Tatwir Altaelim Althaanawii, Masqati, Wizarat Altarbiat Waltaelim, 22-24 Disimbir, 175-190.

Aldaahiri, Salih Hasan (2005). Saykulujiat Altawjih Almahniu Wanazrayatih. Ta1, Eumaana, Dar Wayilun.

Rawaqatu, Ghazi (1994). Madaa Altawafuq Bayn Altafdil Almahnii Wamasarat Altaelim Alththanawii Ladaa Tlbt Alsafi Aleashir Fi Madaris 'lirbad Alhukumiati, Majalat 'Abhath Alyrmuk-Silslat Aleulum Al'iinsaniat Walaijtimaeiati, 11(2), 75 - 95.

Alshirieat, Husayn (1998). Ealaqat Mustawaa Altumuh W Aljins Bialnadj Almahnii Ladaa Tlbt Alsafi Alththani Althaanwi. Al'urdunn. Majalat Mutat Lilbihwth W Aldirasat : Silsilat Aleulum Al'iinsaniat Walaijtimaeiat, 5 (13), 11-33.

Alshareatu, Husayn Salim (2000), Al'amn Alnafsiu Waealaqatuh Biwuduh Alhuiat Almahniati, Mutatan Lildirasat Walbihwith, 15 (3), 157- 205.

Aleatuwm, Eadnan Yusif Waealawinat, Shafiq Falah Waljarahu, Eabdalnaasir Dhiab Wa'abu Ghazal, Mueawiat Mahmud (2005). Eilm Alnafs Altarbuiu (Alnazariat Waltatbiqa). Eumaan, Dar Almasirat.

Alghafri, Sulayman Bin Eali (2005). Alnadj Almahniu Ladaa Tlbt Alsafi Aleashir Bimintaqat Albatinat Bisiltanat Eamman Waealaqatih Bibaed Almutaghayirati, Risalat Majsatayr Ghyr Manshurat, , Jamieat Alsultan Qabaws, Saltanat Eaman.

Karayqr, Lynda Salafiruman (2005). 'lirshad Almawhubin Walmutfawiqin. (Trajmat: Saeid Husni Aleuzat), Eumaan, Dar Althaqafat.

Almarkaz Alwataniu Litanmiat Almawarid Albasharia (D, T), Dalil Tatwir Alwaey Almahni, Sunduq Almalik Eabdallah Alththani Liltanmiat Wawakalat Al'iinma' Alkanadiat Aldawliat. Mashrue Almunari, Al'urdunn.

Masn, Bul Wakunjr, Jun Wakajan, Jirum (2003). 'Usus Sayakulujiat Altufulat Walmurahaqa. (Trjamat: 'Ahmad Ebdalezyz Salam), T3, Alkuayt, Maktabat Alfalah.

Madanat, Haydar Wanasir, 'librahim (1982). 'Athara Aleawamil Alaiqtisadiat Walaijtimaeiat Wamustawaa Taelim Al'abi Watahsil Altaalib Ealaa Aitijah Tlbt Alsafi Alththalith Al'iiedadii Aldhukur Nahw Altaelim Almahnii. Darasat, Aljamieat Al'urduniyati, 2 (11). 65- 78.

Hamisat, Hamd Walbdur, Eabdalhmid (1999). Aitijahat Tlbt Alsafi Aleashir Al'asasia Fi Muhafazat Janub Al'urduni Nahw Altaelim Almahnii Waealaqatiha Bimustawaa Tahsilihim Watafdilihim Almahnii Wamahina Abayahim, Majalat Albihwth Altarbawiat Bijamieat Qutr, 16 (8), 189-222. 


\section{REFERENCES}

Corso, F. V (1989). Career awareness of the sixth-grade student, unpublished master of education, California State university.

Janet, U (2005). Parent/Guardian visualization of career and academic future of seventh graders enrolled in lowachieving schools, the career development quarterly, march 2005, volume 53, p 234- 245.

Lundine, V (2006). Career training and personal planning for students with autism spectrum conditions: a practical resource for schools. Iondon, GBR: Jessica Kingsley Publishers. p96.http://site.ebrary.com/lib/unizwa/Doc?id=10156021\&ppg=96.

Lynda, A. S (1980). Career awareness of Grade nine girls: evaluation of treatment programs. unpublished doctoral dissertation of philosophy, university of Toronto. Canada.

Sheila, B. S (1994). Effect of gender conscious career awareness program on grade five students, unpublished master of education, memorial university of Newfoundland, Newfoundland.

Valenzuela, J \& Coromoto, O (1985). The effect of the elementary school career awareness program as perceived by high school student. unpublished doctoral dissertation of philosophy. University of Pittsburgh. 